\title{
THE EFFECTS OF ROAD DE-ICING SALTS ON TWO AMPHIBIAN SPECIES, RANA SYLVATICA AND RANA PIPIENS, AND THEIR TREMATODE PARASITES
}

By

Dino Milotic

Bachelor of Science, 2014, Ryerson University

\author{
A thesis \\ presented to Ryerson University \\ in partial fulfillment of the \\ requirements for the degree of Master of Science \\ in the Program of \\ Molecular Science \\ Toronto, Ontario, Canada, 2016 \\ (C) Dino Milotic 2016
}




\section{AUTHOR'S DECLARATION}

I hereby declare that I am the sole author of this thesis. This is a true copy of the thesis, including any required final revisions, as accepted by my examiners.

I authorize Ryerson University to lend this thesis to other institutions or individuals for the purpose of scholarly research.

I further authorize Ryerson University to reproduce this thesis by photocopying or by other means, in total or in part, at the request of other institutions or individuals for the purpose of scholarly research.

I understand that my thesis may be made electronically available to the public. 


\begin{abstract}
The effects of road de-icing salts on two amphibian species, Rana sylvatica and Rana pipiens, and their trematode parasites

Master of Science
\end{abstract}

2016

Dino Milotic

Molecular Science

With ongoing amphibian declines, it is essential to determine possible contributors such as diseases and environmental contaminants that may increase susceptibility. A potential contaminant is road salt (mainly $\mathrm{NaCl}$ ), which leaches into aquatic environments. I examined whether road salts make larval amphibians (tadpoles) more susceptible to trematode parasite infection, and also how these affect free-living trematode infectious stages (cercariae). I exposed Rana sylvatica (wood frogs) and R. pipiens (northern leopard frogs) to control, medium (400 $\mathrm{mg} / \mathrm{L})$, and high salt $(800 \mathrm{mg} / \mathrm{L})$ treatments, and then to trematodes. High salt tended to reduce wood frog anti-parasite behaviour and resistance to infection but the opposite was seen for $R$. pipiens, although these tadpoles had elevated lymphocyte counts in high salinity. Trematodes were differentially affected by increased salinities. The results suggest that host-parasiteenvironment interactions are complex, with species differentially affected by contaminants, which may lead to community shifts in predominant hosts and parasite species. 


\section{ACKNOWLEDGEMENTS}

I owe a huge thank you to my supervisor Dr. Janet Koprivnikar, who remained always helpful and always singularly positive and motivating throughout the two years of my master's degree. Dr. Koprivnikar provided excellent guidance and feedback in the beginning planning stages all the way until the end, and it was a pleasure working with her.

I would like to thank my committee members, Dr. Laursen and Dr. Arts, for providing excellent insight during our committee meetings and making sure all concepts were properly covered, and for always being positive entities throughout my degree.

During my degree, I met post-doc Katie O’Dwyer who organized the Ecology Group, which was an excellent way to meet others in the program. Thank you Katie for always offering help when it was needed.

Thank you to my brother Marin Milotic for being an invaluable volunteer during those long summer days and full weeks.

Lastly thank you to my family for being supportive and pushing me to achieve more than I ever dreamed possible. I am tremendously thankful. 


\section{TABLE OF CONTENTS}

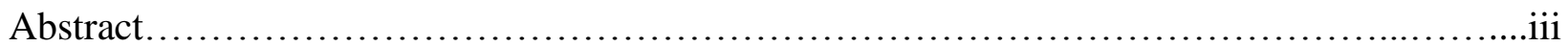

Acknowledgements...............................................................

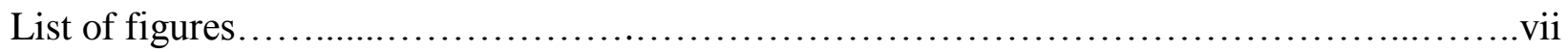

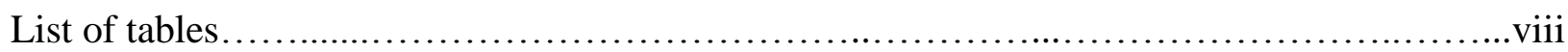

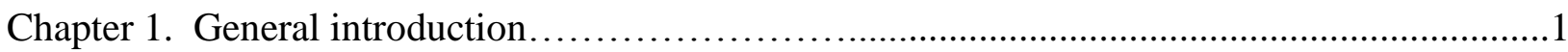

Amphibian diseases........................................................

Road salts in the environment................................................

Main questions................................................................. 8

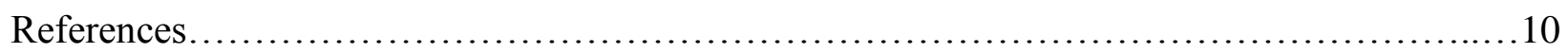

Chapter 2. Effects of road salts on tadpole susceptibility to parasitism.......................16

Materials and methods..................................................... 21

Animal care.......................................................21

Parasite acquisition.................................................22

Road salt field data.................................................22

Experimental Design................................................27

Parasite exposure and behavioural recording ............................28

Data gathering and analysis.........................................29

Results................................................................... 31

Wood frog infection and behaviour...................................... 31

Leopard frog infection and blood profiles............................... 35

Discussion............................................................41

References....................................................................... 48 
Chapter 3. Effects of road salts on a trematode parasite infectious stage .....................55

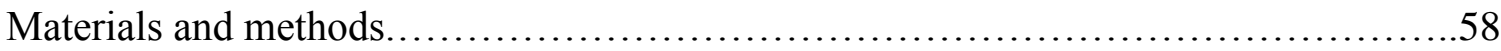

Parasite acquisition...............................................58

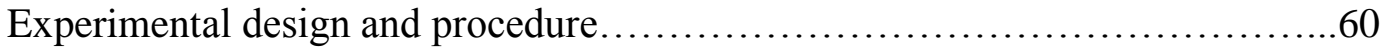

Results............................................................61

Mortality.......................................................6 60

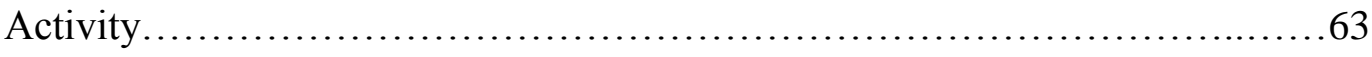

Discussion...........................................................66

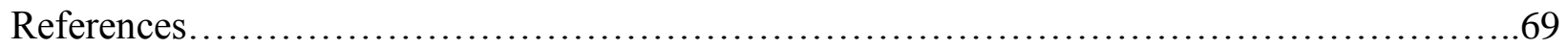

Chapter 4. General discussion, conclusions and future work...........................73

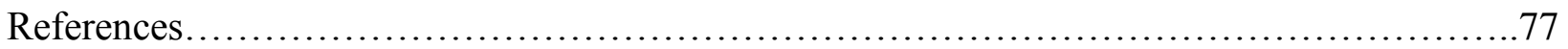




\section{LIST OF FIGURES}

\section{Chapter 1:}

Figure 1.1: Trematode Life Cycle.

\section{Chapter 2}



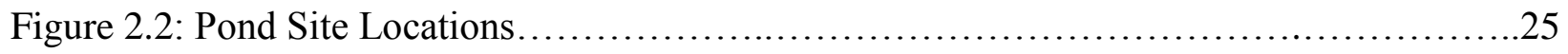

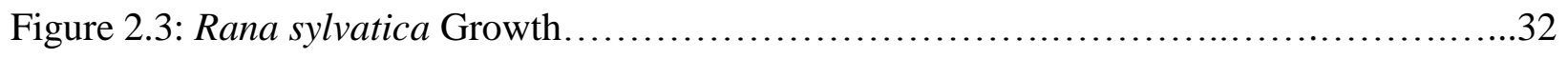

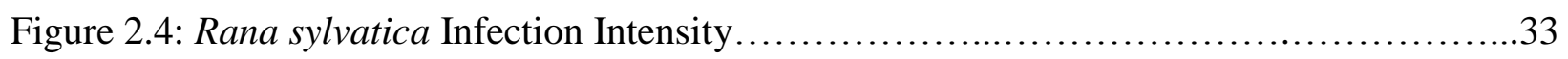

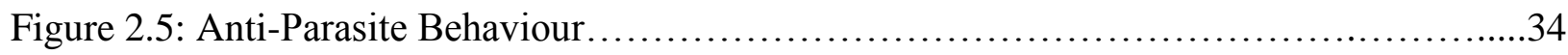

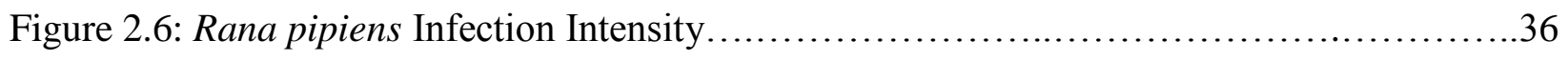

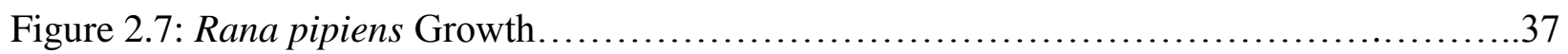

Figure 2.8: Lymphocytes to Red Blood Cells Ratio............................................. 39

Figure 2.9: Total White Blood Cells to Red Blood Cells Ratio................................40

\section{Chapter 3}

Figure 3.1: Armatae-Type Cercariae Alive................................................61

Figure 3.2: Ribeiroia ondatrae Cercariae Alive.............................................62

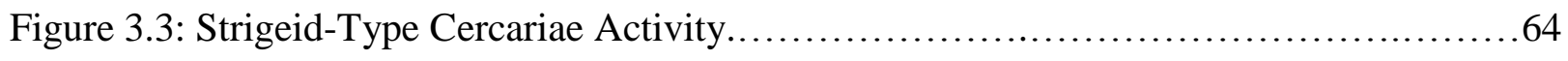

Figure 3.4: Ribeiroia ondatrae Cercariae Activity..........................................65 


\section{LIST OF TABLES}

\section{Chapter 1:}

Table 1.1: Concentrations of Road Salt in Freshwater Aquatic Systems Taken From the

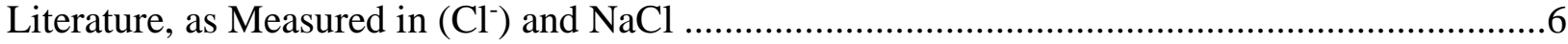

\section{Chapter 2:}

Table 2.1: Details on Pond Type and Location for Field Measurements of $\mathrm{NaCl}$ and

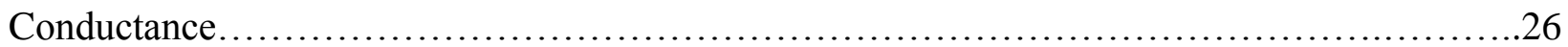




\section{CHAPTER 1: GENERAL INTRODUCTION}

Amphibians are of particular research interest because they are undergoing global declines and as many as $41 \%$ of all amphibian species are in danger of extinction (Stuart et al., 2004; Hoffman et al., 2010). Factors that are contributing to their decline are land-use change (Stuart et al., 2004), disease (Wake and Vredenburg, 2008) and climate change (Li et al., 2013). In particular, a disease caused by a chytrid fungus (Batrachochytrium dendrobatidis) has contributed extensively to amphibian declines (Fisher et al., 2009), but other disease-causing organisms such as various macroparasites are also known to negatively affect amphibians at the individual-and population-level (Koprivnikar et al. 2012). However, these factors do not occur independently, and in conjunction can have interactive effects (Sih et al., 2004).

Anthropogenically-introduced chemicals may increase infection in hosts by affecting their susceptibility and/or tolerance to pathogens. For example, it was found that exposure to atrazine (an herbicide) increased the susceptibility of larval amphibians to infection by trematode parasites (Koprivnikar et al., 2007), which are flatworms with complex multi-host life-cycles (see below) that can have various detrimental effects on amphibians (Johnson et al., 1999; Schotthoefer et al., 2003; Holland et al., 2007). With such a complex interplay between disease and larval amphibians, it is crucial to determine environmental agents may render amphibians more susceptible to infections.

\section{Amphibian diseases}

While amphibian larvae experience abiotic stressors such as contaminants, they encounter additional challenges such as various predators and parasites. Among those of interest are the trematodes - flatworms with complex life cycles (Figure 1.1). Adult trematodes utilize a vertebrate, typically a bird or mammal, as a final host in which sexual reproduction and egg 
shedding occurs. In an aquatic environment, the trematode eggs hatch into motile infective stages called miracidia which locate and infect aquatic mollusks such as snails as their first intermediate host. This trematode undergoes asexual reproduction in infected snails, which shed the second 'form' of the parasite called cercariae. These cercariae are motile, and locate second intermediate hosts such as fish and larval amphibians to infect. Cercariae form metacercariae (cysts) on certain locations on the second intermediate host. Upon predation by a vertebrate final host, the cyst hatches and a mature worm develops to complete the life cycle (Olsen, 1986).

Two trematode species, Ribeiroia ondatrae and Echinostoma trivolvis, are of focus in this thesis because they are known to cause mortality and morbidity in amphibians in natural systems (Blaustein et al., 2012). For example, $R$. ondatrae encysts where hind limb buds develop in tadpoles, which causes malformations of limbs in up to $100 \%$ of infected amphibians at some natural sites (Johnson et al., 1999; Koprivnikar et al. 2012). Malformed amphibians have a disadvantage when escaping predation and may be predated upon more easily than uninfected tadpoles (Johnson et al., 1999). E. trivolvis encysts within tadpole kidneys and pronephroi in which it can disrupt renal function and increase mortality (Schotthoefer et al., 2003; Holland et al., 2007). In the natural environment, a single tadpole may have hundreds of cysts and additional stressors such as contaminants may further exacerbate the decline of amphibians. However, the free-living stages of parasites, such as those of trematodes, are often subject to the same environmental conditions as the hosts. In this case, cercariae and miracidia are exposed to various environmental factors such as fluctuations in $\mathrm{pH}$, oxygen, temperature, salinity, and heavy metals (Pietrock and Marcogliese, 2003) which may influence cercarial longevity and activity. For example, salinity and warmer temperatures in combination were detrimental when cercariae were exposed to these for long periods of time (Koprivnikar et al., 
2010). As the infective period is approximately $8 \mathrm{~h}$ for many species, which is shorter than the cercarial lifespan, reduced longevity reduces the infective period overall (Pietrock and Marcogliese, 2003). 
Figure 1.1: Life cycle of the trematode parasite Ribeiroia ondatrae.

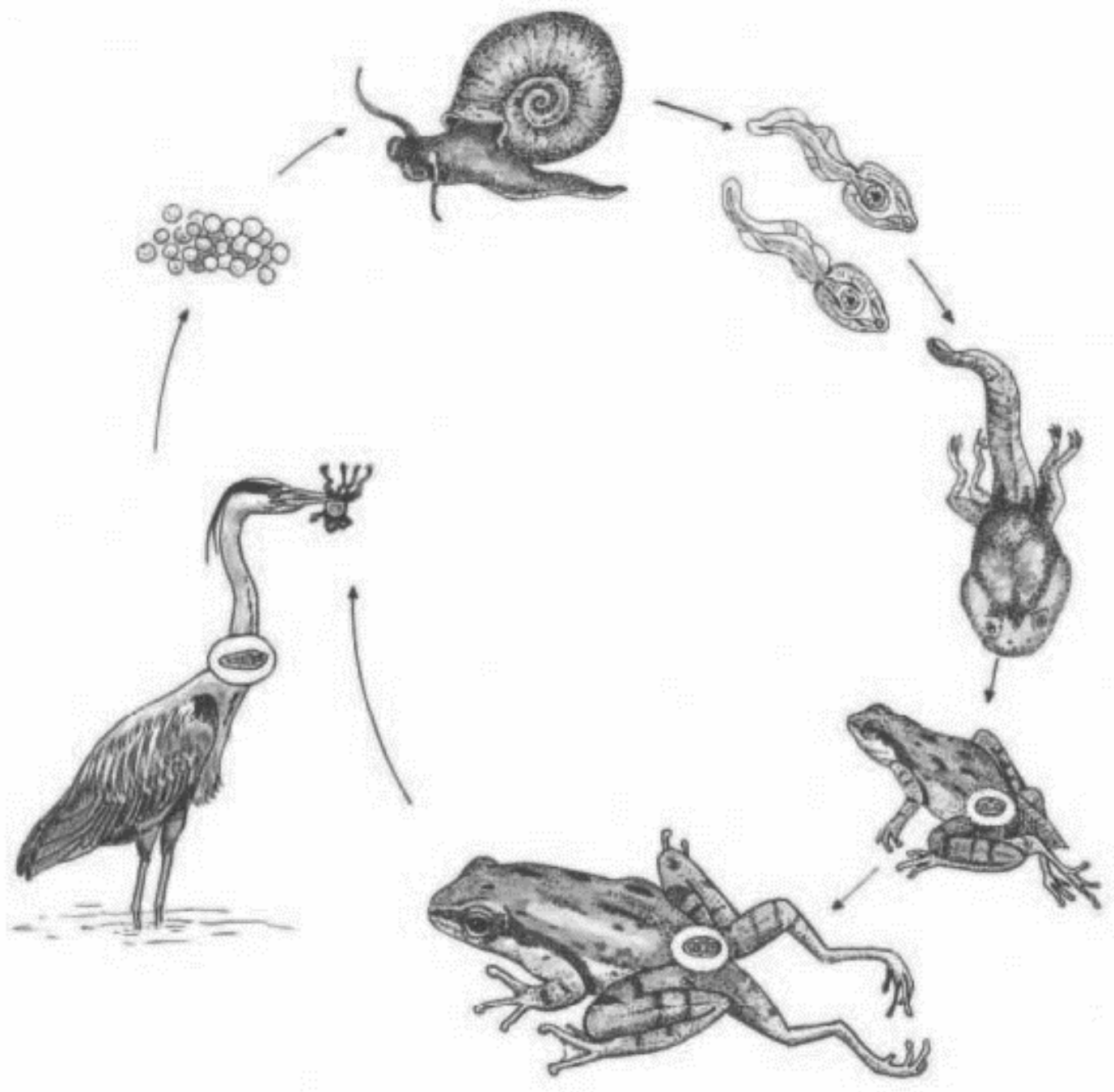

http://www.ecologia.ib.usp.br/ssmb/doku.php?id=2015: groups:g3:start 


\section{Road salts in the environment}

Each year, 592932 tonnes of road salt are applied to roads in the province of Ontario (Environment Canada, 2001), and approximately 2,112,870 tonnes are used Canada-wide (Environment Canada, 2001; Deonël et al., 2010). The most common type of road salt in Canada consists of $\sim 98 \%$ sodium chloride $(\mathrm{NaCl})$, with the remaining $2 \%$ comprised of $\mathrm{CaCl}_{2}$ and/or $\mathrm{MgCl}_{2}$ (Environment Canada, 2001; Sanzo and Hecnar, 2006). Road salt leaches into aquatic environments in many ways, including spring rain and snow melt that wash residues into streams and soil (Findlay and Kelly, 2006; Lax and Peterson, 2009). Further, a buildup of de-icing salts in the soil may displace heavy metals and promote chronic release of $\mathrm{NaCl}$ that may end up in aquatic environments (Findlay and Kelly, 2006). Lastly, road salts may enter aquatic environments through groundwater (Lax and Peterson, 2009). The resulting salt concentrations in aquatic ecosystems can vary specially and temporally among sites, but also temporally. In urban environments, which have a greater proportion of hard surfaces and thus more road salt applied per square meter, nearby waterbodies have elevated chloride content (Howard and Beck, 1993; Williams et al., 1999; Van Meter et al., 2012). Salt concentrations can range from 150 $\mathrm{mg} / \mathrm{L}$ in rural lakes to $5000 \mathrm{mg} / \mathrm{L}$ in urban impoundment lakes and snow cleared from streets (Sanzo and Hecnar, 2006). Concentrations in ponds and wetlands can reach as high as 4000 $\mathrm{mg} / \mathrm{L}$, while streams can reach $4300 \mathrm{mg} / \mathrm{L}$ (Sanzo and Hecnar, 2006). Conductivity, a measure of dissolved solutes, may be 20 times higher in water bodies near roads than those in forests (Karraker et al., 2008). In Wappinger Creek in New York State, salinity levels were found to be higher than ambient in the summer months (Findlay and Kelly, 2011). Table 1.1 lists various $\mathrm{NaCl}$ values from environmental measurements, as well as those used in various toxicity assays. 
Table 1.1: Concentrations of Road Salt in Freshwater Aquatic Systems Taken From the Literature, as Measured in $\left(\mathrm{Cl}^{-}\right)$and $\mathrm{NaCl}$

\begin{tabular}{|c|c|c|}
\hline $\mathrm{NaCl}$ Concentration & $\begin{array}{c}\text { Study Type or Waterbody } \\
\text { Type }\end{array}$ & Reference \\
\hline 1) $0-9750 \mathrm{mg} / \mathrm{L}$ and $0.00-$ & 1) Acute and chronic studies & Sanzo and Hecnar, 2006 \\
\hline $1030.00 \mathrm{mg} / \mathrm{L}$ & 2) Ponds, wetlands and & \\
\hline 2) $4000-4300 \mathrm{mg} / \mathrm{L}$ & streams 3) Rural lake and & \\
\hline 3) 150 and $5000 \mathrm{mg} / \mathrm{L}$ & urban impoundment lake & \\
\hline 500,1000 and $1500 \mathrm{mg} / \mathrm{L}$ & Behavioural studies & Denoël et al., 2010 \\
\hline 2-159 mg/L, 4-261 mg/L $\left(\mathrm{Cl}^{-}\right)$ & Stream & Todd and Kaltencker, 2012 \\
\hline $645 \mathrm{mg} / \mathrm{L}$ & Urban pond & Van Meter et al., 2012 \\
\hline $\begin{array}{c}\text { 1-298 }\left(\mathrm{Na}^{+}\right) \text {and } 1-573 \mathrm{mg} / \mathrm{L} \\
\left(\mathrm{Cl}^{-}\right) \text {in } \mathrm{mg} / \mathrm{L}\end{array}$ & Stream & Daley et al., 2009 \\
\hline$>250 \mathrm{mg} / \mathrm{L}\left(\mathrm{Cl}^{-}\right)$ & Northeast rural stream & Jackson and Jobbágy, 2005 \\
\hline 2 to $1200 \mathrm{mg} / \mathrm{L}\left(\mathrm{Cl}^{-}\right)$ & $\begin{array}{c}\text { Various springs in Greater } \\
\text { Toronto Area }\end{array}$ & Williams et al., 2000 \\
\hline $2840 \mathrm{mg} / \mathrm{L}\left(\mathrm{Cl}^{-}\right)$ & Urban spring & Howard and Beck, 1993 \\
\hline 164 to $1907 \mathrm{mg} / \mathrm{L}$ & Don River (Toronto) & $\begin{array}{c}\text { Warren and Zimmerman, } \\
1994\end{array}$ \\
\hline $\begin{array}{c}28 \mathrm{mg} / \mathrm{L} \text { to over } 2000 \mathrm{mg} / \mathrm{L} \\
\text { and } 370 \mathrm{mg} / \mathrm{L}\end{array}$ & Stream & Meriano et al., 2009 \\
\hline $4000-4300 \mathrm{mg} / \mathrm{L}$ & Ponds, wetlands and streams & Sanzo and Hecnar, 2006 \\
\hline
\end{tabular}


Chloride is often used as a proxy for how much road salt has entered water bodies, as $60 \%$ of $\mathrm{NaCl}$ is chloride by weight, which more readily leaches into aquatic environments (Lax and Peterson, 2009). Elevated chloride can have negative effects on vertebrate and macroinvertebrate community structure, as well as on algae and protozoans (Findlay and Kelly, 2011). Freshwater organisms are hyperosmotic relative to the aquatic environment and chloride regulation occurs through either active pumps or bicarbonate exchange pumps on gills, and when this mechanism is overwhelmed by excess chloride, then it becomes toxic (see Elphic et al., 2011 for more details). Canadian water quality guidelines predict $95 \%$ of species will not be adversely harmed if chloride levels are maintained below $212.6 \mathrm{mg} / \mathrm{L}$, using a species sensitivity distribution curve (see Elphic et al., 2011 for more details). For instance, a significant number or protozoans and plants did not germinate at salinities $(\mathrm{NaCl})$ of $300-5000 \mathrm{mg} / \mathrm{L}$ (Brock et al., 2005), while Chand et al. (2015) found that a prawn (Macrobrachium rosenbergii) had survival rates of $6-17 \%$ and $79-83 \%$ in $25-26$ ppt and $21-22 \mathrm{ppt}(\mathrm{NaCl})$ respectively. The mechanism for negative effect for the latter was suggested as energy allocation from protein and lipid production into osmoregulation (Chand et al., 2015). Organisms that breed in the summer, or are in relatively sensitive stages in the life cycle, are more likely to be harmed by exposure to elevated salinity (Findlay and Kelly, 2011). Species richness is negatively correlated with chloride concentrations, but positively correlated with distance from roads, implying that elevated chloride deters or eliminates species (Sanzo and Hecnar, 2006).

Amphibians also show detrimental effects of high $\mathrm{NaCl}$ exposure (Brand et al., 2010). For example, wood frogs (Rana sylvatica) experience $50 \%$ mortality at $4300 \mathrm{mg} / \mathrm{L}$, and this occurs for American toads (Bufo americanus) at 10000 mg/L over 96 hours (Brand et al., 2010). Moreover, tadpoles of wood frogs and southern toads (Anaxyrus terrestris) reared in road salt 
solutions were found to have reduced activity and responsiveness to prodding, had accelerated metamorphosis, and physical abnormalities (Sanzo and Hecnar, 2006; Findlay and Kelly, 2011; Wood and Welch, 2015). Exposure to road salt places larval amphibians in an osmotically adverse environment which could cause stress. As a response to osmotic stress, hormones might be released in tadpoles that are known to act as immunosuppressive agents in amphibians (Bennet and Johnson, 1973; LaFonte and Johnson, 2013). Moreover, stressful conditions might shift energy allocations such that more energy is invested into osmoregulation and less in behaviour, and behaviour is known to play a key role in avoiding parasites for larval amphibians (Koprivnikar et al, 2014).

Freshwater parasites are harmed by increased salinities as well, while saline-inhabiting (marine) parasites are harmed by dilution (Shostak, 1993; Pietrock and Marcogliese, 2003; Studer and Poulin, 2012). Furthermore, terrestrial species, such as plants and other sessile organisms experience increased mortality by exposure to saline conditions (Munch, et al., 2009). High levels of $\mathrm{NaCl}$ can also have indirect effects on water quality. For example, $\mathrm{Na}^{+}$may displace potassium $(\mathrm{K})$, magnesium $(\mathrm{Mg})$, lead $(\mathrm{Pb})$, and other positively charged ions in soil, and the displacement of $\mathrm{NH}_{4}{ }^{+}$which is readily taken up by primary producers and converted to $\mathrm{NO}_{3}{ }^{-}$, and $\mathrm{NO}_{3}{ }^{-}$leaches more easily through soil (Findlay and Kelly, 2011). In this form, it travels through the soil and into the water and may deplete local nitrogen concentrations (Findlay and Kelly, 2011).

\section{Main questions}

Because of its common presence in freshwater, and the importance of parasites for amphibian populations, I wanted to study how road salt might affect the interaction between larval amphibians and their trematode parasites that are known to be common throughout North 
America and cause harm (Koprivnikar et al. 2012). Does road salt affect the susceptibility of tadpoles to trematode parasites, and if so, what is the underlying mechanism? Will road salt stress tadpoles and act as an immune suppressant, or will it act through lowering anti-parasite behaviour? It is known that anti-parasite behaviour is effective in reducing parasite loads (Koprivnikar et al., 2014), and that stress lowers immunocompetence in amphibians which leads to greater parasitism (LaFonte and Johnson, 2013).

In Chapter 2, I examined behaviour, growth, and infection of wood frogs (Rana sylvatica) by Ribeiroia ondatrae, as well as growth, blood profiles, and infection by Echinostoma trivolvis in northern leopard frogs (Rana pipiens). I hypothesized that road salts would increase susceptibility of larval amphibians to trematode infections by acting as an immunosuppressant through the stress of elevated salinity, and also by lowering their anti-parasite behaviour. In Chapter 3, I examined how road salt might affect the activity and survival of trematode cercariae (Ribeiroia ondatrae, Echinostoma trivolvis, armatae-type and strigeid-type cercariae). I anticipated that relatively high salinity based of literature values (up to $800 \mathrm{mg} / \mathrm{L}$ of $\mathrm{NaCl}$ ) would be detrimental to the freshwater trematodes used in this study, reducing their longevity and activity 


\section{References:}

Bennett, M. F., \& Johnson, A. O. (1973). Osmotic stress, ACTH and the white blood cell picture in newts, Notophthalmus viridescens. Journal of Comparative Physiology, 82, 333-338.

Blaustein, A. R., Gervasi, S. S., Johnson, P. T. J., Hoverman, J. T., Belden, L. K., Bradley, P. W., \& Xie, G. Y. (2012). Ecophysiology meets conservation: Understanding the role of disease in amphibian population declines. Philosophical Transactions of the Royal Society B: Biological Sciences, 367, 1688-1707.

Brand, A. B., Snodgrass, J. W., Gallagher, M. T., Casey, R. E., \& Van Meter, R. (2010). Lethal and sublethal effects of embryonic and larval exposure of Hyla versicolor to stormwater pond sediments. Archives of Environmental Contamination and Toxicology, 58, 325-331.

Brock, M. A., Nielsen, D. L., \& Crosslé, K. (2005). Changes in biotic communities developing from freshwater wetland sediments under experimental salinity and water regimes. Freshwater Biology, 50, 1376-1390.

Chand, B. K., Trivedi, R. K., Dubey, S. K., Rout, S. K., Beg, M. M., \& Das, U. K. (2015). Effect of salinity on survival and growth of giant freshwater prawn Macrobrachium rosenbergii (de man). Aquaculture Reports, 2, 26-33. Daley, M. L., Potter, J. D., \& McDowell, W. H. (2009). Salinization of urbanizing New Hampshire streams and groundwater: Effects of road salt and hydrologic variability. Journal of the North American Benthological Society, 28, 929-940. Denoël, M., Bichot, M., Ficetola, G. F., Delcourt, J., Ylieff, M., Kestemont, P., \& Poncin, P. (2010). Cumulative effects of road de-icing salt on amphibian behavior. Aquatic Toxicology, 99, $275-280$.

Elphick, J. R., Bergh, K. D., \& Bailey, H. C. (2011). Chronic toxicity of chloride to freshwater species: Effects of hardness and implications for water quality guidelines. Environmental 
Toxicology and Chemistry, 30, 239-246. Environment Csanada, (2001) Environment Canada, Priority substance list Assessment Report Road Salts, Environment Canada, Ottawa, Canada. Findlay, S. E. G., \& Kelly, V. R. (2011). Emerging indirect and long-term road salt effects on ecosystems. Annals of New York Academy of Sciences, 1223, 58-68.

Fisher, M. C., Garner, T. W. J., \& Walker, S. F. (2009). Global emergence of Batrachochytrium dendrobatidis and amphibian chytridiomycosis in space, time, and host. Annual Review of Microbiology, 63, 291-310.

Hoffmann, M., Hilton-Taylor, C., Angulo, A., Böhm, M., Brooks, T.M., Butchart, S.H.M., Carpenter, K.E., Chanson, J., Collen, B., Cox, N.A., Darwall, W.R.T., Dulvy, N.K., Harrison, L.R., Katariya, V., Pollock, C.M., Quader, S., Richman, N.I., Rodrigues, A.S.L., Tognelli, M.F., Vié, J.-C., Aguiar, J.M., Allen, D.J., Allen, G.R., Amori, G., Ananjeva, N.B., Andreone, F., Andrew, P., Ortiz, A.L.A., Baillie, J.E.M., Baldi, R., Bell, B.D., Biju,S.D., Bird, J.P., BlackDecima, P., Blanc, J.J., Bolaños, F., Bolivar-G., W., Burfield, I.J., Burton, J.A., Capper, D.R., Castro, F., Catullo, G., Cavanagh, R.D., Channing, A., Chao, N.L., Chenery, A.M., Chiozza, F., Clausnitzer, V., Collar, N.J., Collett, L.C., Collette, B.B., Cortez Fernandez, C.F., Craig, M.T., Crosby, M.J., Cumberlidge, N., Cuttelod, A., Derocher, A.E., Diesmos, A.C., Donaldson, J.S., Duckworth, J.W., Dutson, G., Dutta, S.K., Emslie, R.H., Farjon, A., Fowler, S., Freyhof, J., Garshelis, D.L., Gerlach, J., Gower, D.J., Grant, T.D., Hammerson, G.A., Harris, R.B., Heaney, L.R., Hedges, S.B., Hero, J.-M., Hughes, B., Hussain, S.A., Icochea M., J., Inger, R.F., Ishii, N., Iskandar, D.T., Jenkins, R.K.B., Kaneko, Y., Kottelat, M., Kovacs, K.M., Kuzmin, S.L., La Marca, E., Lamoreux, J.F., Lau, M.W.N., Lavilla, E.O., Leus, K., Lewison, R.L., Lichtenstein, G., Livingstone, S.R., Lukoschek, V., Mallon, D.P., McGowan, P.J.K., McIvor, A., Moehlman, P.D., Molur, S., Alonso, A.M., Musick, J.A., Nowell, K., Nussbaum, R.A., Olech, W., Orlov, 
N.L., Papenfuss, T.J., Parra-Olea, G., Perrin, W.F., Polidoro, B.A., Pourkazemi, M., Racey, P.A., Ragle, J.S., Ram, M., Rathbun, G., Reynolds, R.P., Rhodin, A.G.J., Richards, S.J., Rodríguez, L.O., Ron, S.R., Rondinini, C., Rylands, A.B., De Mitcheson, Y.S., Sanciangco, J.C.e, Sanders, K.L., Santos-Barrera, G., Schipper, J., Self-Sullivan, C., Shi, Y., Shoemaker, A., Short, F.T., Sillero-Zubiri, C., Silvano, D.L., Smith, K.G., Smith, A.T., Snoeks, J., Stattersfield, A.J., Symes, A.J., Taber, A.B., Talukdar, B.K., Temple, H.J., Timmins, R., Tobias, J.A., Tsytsulina, K., Tweddle, D., Ubeda, C., Valenti, S.V., Van Dijk, P.P., Veiga, L.M., Veloso, A., Wege, D.C., Wilkinson, M., Williamson, E.A., Xie, F., Young, B.E., Akçakaya, H.R., Bennun, L., Blackburn, T.M., Boitani, L., Dublin, H.T., Da Fonseca, G.A.B., Gascon, C., Lacher Jr., T.E., Mace, G.M., Mainka, S.A., McNeely, J.A., Mittermeier, R.A., Reid, G.M., Rodriguez, J.P., Rosenberg, A.A., Samways, M.J., Smart, J., Stein, B.A., \& Stuart, S.N. (2010). The impact of conservation on the status of the world's vertebrates. Science, 330, 1503-1509.

Howard, K. W. F., \& Beck, P. J. (1993). Hydrogeochemical implications of groundwater contamination by road de-icing chemicals. Journal of Contaminant Hydrology, 12, 245-268. Jackson, R. B., \& Jobbágy, E. G. (2005). From icy roads to salty streams. Proceedings of the National Academy of Sciences of the United States of America, 102, 14487-14488.

Johnson, P. T. J., Lunde, K. B., Ritchie, E. G., \& Launer, A. E. (1999). The effect of trematode infection on amphibian limb development and survivorship. Science, 284, 802-804.

Koprivnikar, J., Forbes, M. R., \& R. L. Baker. (2007) Contaminant effects on host-parasite interactions: atrazine, frogs and trematodes. Environmental Toxicology and Chemistry, 26, 21662170.

Koprivnikar, J., D. Lim, C. Fu, and S. H. M. Brack. (2010) Effects of temperature, salinity, and $\mathrm{pH}$ on the survival and activity of marine cercariae. Parasitology Research 106: 1167-1177. 
Koprivnikar, J., Redfern, J. C., \& Mazier, H. L. (2014). Variation in anti-parasite behaviour and infection among larval amphibian species. Oecologia, 174, 1179-1185.

LaFonte, B. E., \& Johnson, P. T. J. (2013). Experimental infection dynamics: Using immunosuppression and in vivo parasite tracking to understand host resistance in an amphibiantrematode system. Journal of Experimental Biology, 216, 3700-3708.

Li, Y., Cohen, J. M., \& Rohr, J. R. (2013). Review and synthesis of the effects of climate change on amphibians. Integrative Zoology, 8, 145-161.

Olsen, O.W., 1986. Animal parasites: Their life cycles and ecology. Courier Corporation. 562. Meriano, M., Eyles, N., \& Howard, K. W. F. (2009). Hydrogeological impacts of road salt from Canada's busiest highway on a lake Ontario watershed (Frenchman's bay) and lagoon, city of Pickering. Journal of Contaminant Hydrology, 107, 66-81.

Munck, I. A., Bennett, C. M., Camilli, K. S., \& Nowak, R. S. (2010). Long-term impact of deicing salts on tree health in the Lake Tahoe basin: Environmental influences and interactions with insects and diseases. Forest Ecology and Management, 260, 1218-1229.

Pietrock, M., \& Marcogliese, D. J. (2003). Free-living endohelminth stages: At the mercy of environmental conditions. Trends in Parasitology, 19, 293-299.

Sanzo, D., \& Hecnar, S. J. (2006). Effects of road de-icing salt (NaCl) on larval wood frogs (Rana sylvatica). Environmental Pollution, 140, 247-256.

Sih, A., Bell, A.M., \& Kerby, J.L., (2004). Two stressors are far deadlier than one. Trends in Ecology \& Evolution, 19, 274-276.

Shostak, A.W., (1993). Survival of Petasiger nitidus (Digenea: Echinostomatidae) cercariae in relation to temperature, $\mathrm{pH}$, and salinity. Canadian Journal of Zoology, 71, 431-434. 
Skerratt, L. F., Berger, L., Speare, R., Cashins, S., McDonald, K. R., Phillott, A. D., Hines H.B., \& Kenyon, N. (2007). Spread of chytridiomycosis has caused the rapid global decline and extinction of frogs. EcoHealth, 4, 125-134.

Stuart, S.N., Chanson, J.S., Cox, N.A., Young, B.E., Rodrigues, A.S.L., Fischman, D.L., \& Waller, R.W. (2004). Status and trends of amphibian declines and extinctions worldwide. Science, 306, 1783-1786.

Studer, A., \& Poulin, R., 2012. Effects of salinity on an intertidal host-parasite system: Is the parasite more sensitive than its host? Journal of Experimental Marine Biology and Ecology, 412, $110-116$.

Todd, A. K., \& Kaltenecker, M. G. (2012). Warm season chloride concentrations in stream habitats of freshwater mussel species at risk. Environmental Pollution, 171, 199-206.

Wake, D.B., \& Vredenburg, V.T. (2008). Are we in the midst of the sixth mass extinction? A view from the world of amphibians. Proceedings of the National Academy of the Sciences of the U.S.A., 105, 11466-11473.

Warren, L. A., \& Zimmerman, A. P. (1994). The influence of temperature and $\mathrm{NaCl}$ on cadmium, copper and zinc partitioning among suspended particulate and dissolved phases in an urban river. Water Research, 28, 1921-1931.

Williams, D. D., Williams, N. E., \& Cao, Y. (2000). Road salt contamination of groundwater in a major metropolitan area and development of a biological index to monitor its impact. Water Research, 34, 127-138.

Wood, L., \& Welch, A. M. (2015). Assessment of interactive effects of elevated salinity and three pesticides on life history and behavior of southern toad (Anaxyrus terrestris) tadpoles. Environmental Toxicology and Chemistry, 34, 667-676. 
Van Meter, R. J., Swan, C. M., Leips, J., \& Snodgrass, J. W. (2011). Road salt stress induces novel food web structure and interactions. Wetlands, 31, 843-851.

Van Meter, R. J., Swan, C. M., \& Trossen, C. A. (2012). Effects of road deicer (NaCl) and amphibian grazers on detritus processing in pond mesocosms. Environmental Toxicology and Chemistry, 31, 2306-2310. 


\section{CHAPTER 2: EFFECTS OF ROAD SALTS ON LARVAL AMPHIBIAN SUSCEPTIBILITY TO PARASITISM}

\section{Introduction:}

Amphibian habitats are undergoing anthropogenic disturbances that are related to degradation and the introduction of contaminants (Semlitsch, 2000; Koprivnikar et al., 2007). As a result, amphibians may be more susceptible and/or less tolerant to diseases. For example, a pesticide used in agricultural fields has been shown to increase amphibian susceptibility to parasite infection by reducing immunocompetence (Kiesecker, 2002). For example, the herbicide atrazine has been shown to increase susceptibility of larval amphibians to trematode infection (Koprivnikar et al., 2007). This is important because amphibians are undergoing global declines, and infectious diseases have been implicated (Daszak et al., 1999, Daszak et al., 2003). Two trematode species, Ribeiroia ondatrae and Echinostoma trivolvis, are of particular interest because of the mortality and pathology associated with infection (Johnson et al., 1999; Schotthoefer et al., 2003). $R$. ondatrae encysts around developing hind limb buds which results in deformities that reduce amphibian viability and increase mortality (Johnson et al., 1999). E. trivolvis encysts in the kidney and proneprhoi, which disrupts renal function and often leads to mortality at high intensities of infection (Schotthoefer et al., 2003). Factors that impact host susceptibility to infection by trematode parasites are important to consider in this context because they could further drive declines in amphibian populations.

Human encroachment often occurs on natural habitats used by amphibians to breed and develop during their aquatic larval stage (Haynes et al., 2010). These water bodies are often close to roads that require the use of road salts during winter months. During the spring snow melt, the road salts and other contaminants end up in these aquatic habitats, with soil and forests also 
serving as an ongoing source of salinity owing to salt retention and later release (Bastyiken et al., 2006; Lax and Peterson, 2009; Findlay and Kelly, 2011). Concentrations found in nature as a result of anthropogenic introduction of road salts range from $0-4,300 \mathrm{mg} / \mathrm{L}$, with lower values in rural areas and higher values in urban areas (see Chapter 1, Table 1). The resulting increases in conductance (overall dissolved solutes) and salinity have known detrimental effects on larval amphibians. For example, conductance may affect competition outcomes, mating behaviour, growth, development, osmotic regulation, and survivorship (Wallace 1991; Jørgensen, 1997; Gómez and Tejedo, 2002; Karraker et al., 2008; Snodgrass et al., 2008). Amphibian skin is highly permeable, and ions that enter can disrupt the nervous system and other physiological functions (Denoël et al., 2010). As a whole, amphibians cannot tolerate more than $30 \%$ of the salinity that is found in marine environments (Sanzo and Hecnar, 2006). For example, Rana sylvatica (wood frog) tadpoles metamorphosed sooner in saline conditions (Sanzo and Hecnar, 2006), and tadpoles of southern toad (Anaxyrus terrestris) reared in elevated salinity were smaller, less active, and had a smaller size at metamorphosis (Wood and Welch, 2015). In general, detrimental effects on amphibians may be expected beginning at salt concentrations of $686 \mathrm{mg} / \mathrm{mL}$ (Findlay and Kelly, 2011). The lethal concentration for 50\% of mortality to occur (LC50) over 96 hours for wood frog tadpoles was 4, $300 \mathrm{mg} / \mathrm{L}$, while that for the American toad (Bufo americanus) was 10, $000 \mathrm{mg} / \mathrm{L}$ over 96 hours (Brand et al., 2010). Further, amphibian larvae are particularly sensitive to elevated salinity in their early developmental stages as it may interfere with water regulation as well as embryonic development (Padhye and Ghate, 1992). In another study, wood frogs were exposed to $\mathrm{NaCl}$ concentrations of $0-9,750 \mathrm{mg} / \mathrm{L}$ for acute toxicity assays, and $0.00,0.39,77.50,1030.00 \mathrm{mg} / \mathrm{L}$ for a chronic assay (Sanzo and Hecnar, 2006). The LC50 values in 96 hours for this study were 2, $636 \mathrm{mg} / \mathrm{mL}$ 
and 5, $109 \mathrm{mg} / \mathrm{mL}$, respectively (Sanzo and Hecnar, 2006). Tadpoles were less active, had reduced weight, accelerated metamorphosis, and also had physical abnormalities (Sanzo and Hecnar, 2006).

When environmental conditions are no longer optimal, organisms often experience stress as a mechanism to cope with certain physiological needs. For example, stress is associated with glucocorticoid hormones such as corticosterone, which tends to reduces growth and increase energy utilization (metabolism) in amphibians by tapping into energy reserves (Glennemeier and Denver, 2002). Corticosterone also causes changes in behaviour (Moore and Miller, 1984), which is a major consideration for the ability of animals to carry out day to day tasks. Other factors such as growth and development (Glennemeier and Denver, 2002) and components of the immune system (Tournefier, 1982; Ducoroy et al., 1999) are altered. Furthermore, increased levels of corticosterone are implicated in pathways that regulate osmotic stress (Ultsch et al., 1999), which is important if one considers the potential effects of road salts on aquatic vertebrates.

Since amphibian larvae are hyperosmotic relative to their ambient concentrations, the maintenance of $\mathrm{Na}^{+}$levels becomes crucial when faced with more saline conditions (Ultsch et al., 1999). The total $\mathrm{Na}^{+}$content of Rana pipiens whole body content found to be $1365-1815$ micromolar/g and is $400-800$ micromolar/g of dry body weight for $R$. sylvatica. $\mathrm{Cl}^{-}$content is unavailable for Rana pipiens, but was 300 - 825 micromole/g of dry body weight for Rana sylvatica (Freda and Dunson, 1984). These values suggest that amphibians are hyperosmotic to their freshwater environment. The plasma of Litoria caerulea was found to have 102.8

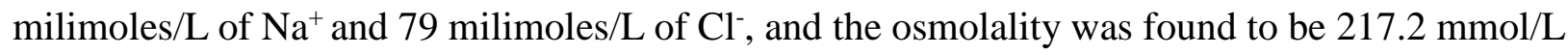
(Voyles et al., 2007. These values are generally consistent with other studies examining different 
amphibian species (Hronowsi and Armstrong, 1977; Gomez-Mastre, et al., 2004). The uptake of $\mathrm{Na}^{+}$is replaced by the expulsion of $\mathrm{Na}^{+}$from the body in hypersaline conditions and this regulatory shift causes stress, including an increase in corticosterone (Ultsch et al., 1999). The energy used in more demanding osmoregulation could thus otherwise be used in other processes such as growth and development

Increases in stress hormones such as corticosterone have important implications for many animals, including amphibians, because organisms typically have limited energy reserves and allocation of energy for a physiological response due to stressors may leave less energy for maintenance of a normal system. For example, elevated glucocorticoids promote energy utilization for critical functions that enhance survival under adverse conditions, but at the expense of growth and reproduction (Moore and Jessop, 2003). Furthermore, corticosterone levels in larval northern leopard frogs (R. pipiens) increased in the presence of competition, which reduced growth but not development (Glennemeier and Denver, 2002). Chronicallyelevated glucocorticoids may influence cytokine synthesis (Maule and VanderKooi, 1999), reduce antibody production and T-cell proliferation (Ottaviani and Franceschi, 1996; Maule and VanderKooi, 1999), and reduce inflammatory responses (Mastorakos et al., 1999). In northern leopard frogs and bullfrogs, exogenous hydrocortisone treatment caused an increase in neutrophils and a decrease in lymphocytes, but levels normalized within three days (Bennet and Johnson, 1973).

Alterations of stress hormones not only impact the composition of white blood cells, but also have implications for the ability of animals to resist and tolerate pathogens such as parasites, which has been demonstrated in larval amphibians. For instance, exogenous corticosterone increased the susceptibility of grey tree frog (Hyla versicolor) tadpoles to infection by the 
trematode parasite Alaria sp., and was associated with a decrease in eosinophil leukocytes - an indication of a suppressed immune system (Belden and Kiesecker, 2005). In another study, application of corticosterone tripled the susceptibility of grey tree frog tadpoles to three different trematode species, with $R$. ondatrae being especially virulent (LaFonte and Johnson, 2013). Corticosterone treatment caused immunosuppression that was characterised by a $62 \%$ reduction in eosinophils (LaFonte and Johnson, 2013). Thus, elevated levels of stress hormones such as glucocorticoids may suppress the immune system and increase disease susceptibility, which may play a role in recent declines and parasite-induced malformations in amphibians (Belden and Kiesecker, 2005; LaFonte and Johnson, 2013).

Environmental perturbations cause stress, and stressed animals exhibit atypical actions such as reduced activity, interest in mating, and foraging, which implies that stressful conditions have implications for animal behaviour (Ditchkoff et al., 2006; Dantzer et al., 2008). Moreover, infected animals exhibit these types of behaviours as well because they are stressed. Many animals that are infected with pathogens or parasites may start to behave unusually, including changes in foraging behaviour, reduced activity levels, and reduced interest in sexual reproduction (see review by Moore, 2002). Such "sickness behaviour" can be triggered by changes in corticosterone levels (Johnson et al., 1996), as well as the production of proinflammatory cytokines which are produced by activated leukocytes (Kent et al., 1992). However, aside from innate immunity, animals also exhibit highly-effective anti-parasite behaviours. For example, larval amphibians employ anti-parasite behaviours in the presence of parasites, which includes increased activity levels and rapid tail movement which has been shown to greatly reduce infections rates in tadpoles that exhibit this behaviour compared to those that do not (Taylor et al., 2004; Koprivnikar et al., 2014). 
Because road salts can accumulate in very high concentrations in water bodies used by amphibians for breeding, and are known to have various detrimental effects on their survivorship and development during short-term acute exposures, I decided to examine potential sub-lethal effects of chronic exposure with respect to host susceptibility to parasitism. Using environmentally-realistic concentrations, I exposed larvae of $R$. pipiens and $R$. sylvatica to chronic treatments of road salt that might be expected to cause stress which could be immunosuppressive, and investigated tadpole growth and resistance to infection by trematode parasites. I hypothesised that road de-icing salts would act as an immunosuppressant and also reduce anti-parasite behavior, resulting in a higher susceptibility of larval amphibians to trematode infections.

\section{Materials and methods:}

Animal care

Wood frog (Rana sylvatica) egg masses were obtained from a commercial supplier (Boreal Science) and were reared in $15 \mathrm{~L}$ plastic tubs containing dechlorinated water on a 14:10 light/dark cycle until hatching. Hatched tadpoles were separated into twelve aerated tubs containing dechlorinated water at densities of approximately 70 tadpoles per tub. Tadpoles were fed 2-3 pieces of rabbit chow every other day for about three weeks after which their diet was replaced with boiled spinach and fish flakes ad libitum until the majority reached Gosner developmental stage 28 (Gosner, 1960) and were then fed raw spinach. All tubs received water changes every two days, with alternating half and full water changes. Northern leopard frog $(R$. pipiens) tadpoles (stage 24/25) were acquired from egg masses obtained by an experimental breeding study conducted by another lab (see Trudeau et al., 2013) and maintained separately in the same way as the wood frog tadpoles. 


\section{Parasite acquisition}

Aquatic snails (Helisoma trivolvis) were acquired from a field site in St. Catherines, Ontario and screened for trematode infection by placing individuals into a Petri dish with dechlorinated water under a 60W incandescent lamp for one hour. For snails harbouring infections (i.e. confirmed by cercariae emergence), the trematode species were identified using a compound microscope and identification keys (Schell, 1985), and the snails were separated according to which cercariae they carried. Snails that released Ribeiroia ondatrae cercariae were then kept separately in a 2 L container of dechlorinated water and fed raw spinach, with water changes every 4 days. When $R$. ondatrae cercariae were needed for experimental procedures, snails were left overnight in Petri dishes in the dark and cercariae were collected early next morning (7 a.m.). Snails were also collected from a field site near Cambridge, Ontario and were screened for infection by the same methods, with those infected with Echinostoma trivolvis also kept separately. Cercariae of E. trivolvis were then obtained when needed by placing infected snails under lamps as described above, the morning of the experiment.

\section{Road salt field data}

Field road salt concentrations were gathered from 10 ponds near Guelph (ON) at two times in 2015 (Figures 2.1 and 2.2). A conductance probe and a $\mathrm{NaCl}$ probe (VWR Traceable ${ }^{\circledR}$ Salinity Meter and VWR Traceable ${ }^{\circledR}$ Conductance Meter) were used at each site to measure littoral zone conductance and $\mathrm{NaCl}$ values in May and June. In addition to $\mathrm{NaCl}$ measures, the following information was obtained for each site: mean agricultural distance (using the closest crop/pasture field to the north, south, east, and west of the pond), and distance to the closest agricultural field (any direction). These data were obtained during a previous using the same 10 sites (see Koprivnikar and Redfern, 2012 
for details) and are summarized in Table 1.2. Because the sites that were categorized as agricultural had a mean distance of $35.3 \mathrm{~m}( \pm 21.3$ S.D. $)$ to the nearest crop/pasture field in any in any direction (range 13.4-70 m), while the non-agricultural ones were an average of $211.1 \mathrm{~m}$ away ( \pm 64.9 S.D; range 104.9-280 $\mathrm{m}$ ), this information also justifies the classification of all ponds $>75 \mathrm{~m}$ from such fields as non-agricultural, in addition to maintaining consistency with other studies in this respect (King, et al., 2007, 2008; Meyer, et al., 2015). In other words, a clear set of ponds was less than $75 \mathrm{~m}$ from agricultural activity while the other set was at least $105 \mathrm{~m}$ away, and often more, with a significant difference between the two site classifications in this measure $(t=5.755, \mathrm{df}=8, \mathrm{P}<0.001)$. 
Figure 2.1: Field $\mathrm{NaCl}$ values measured in May and June of 2015. Numbered sites indicate ponds with agricultural fields nearby (see text for definitions) and lettered ponds indicate ponds non-adjacent to agricultural fields.

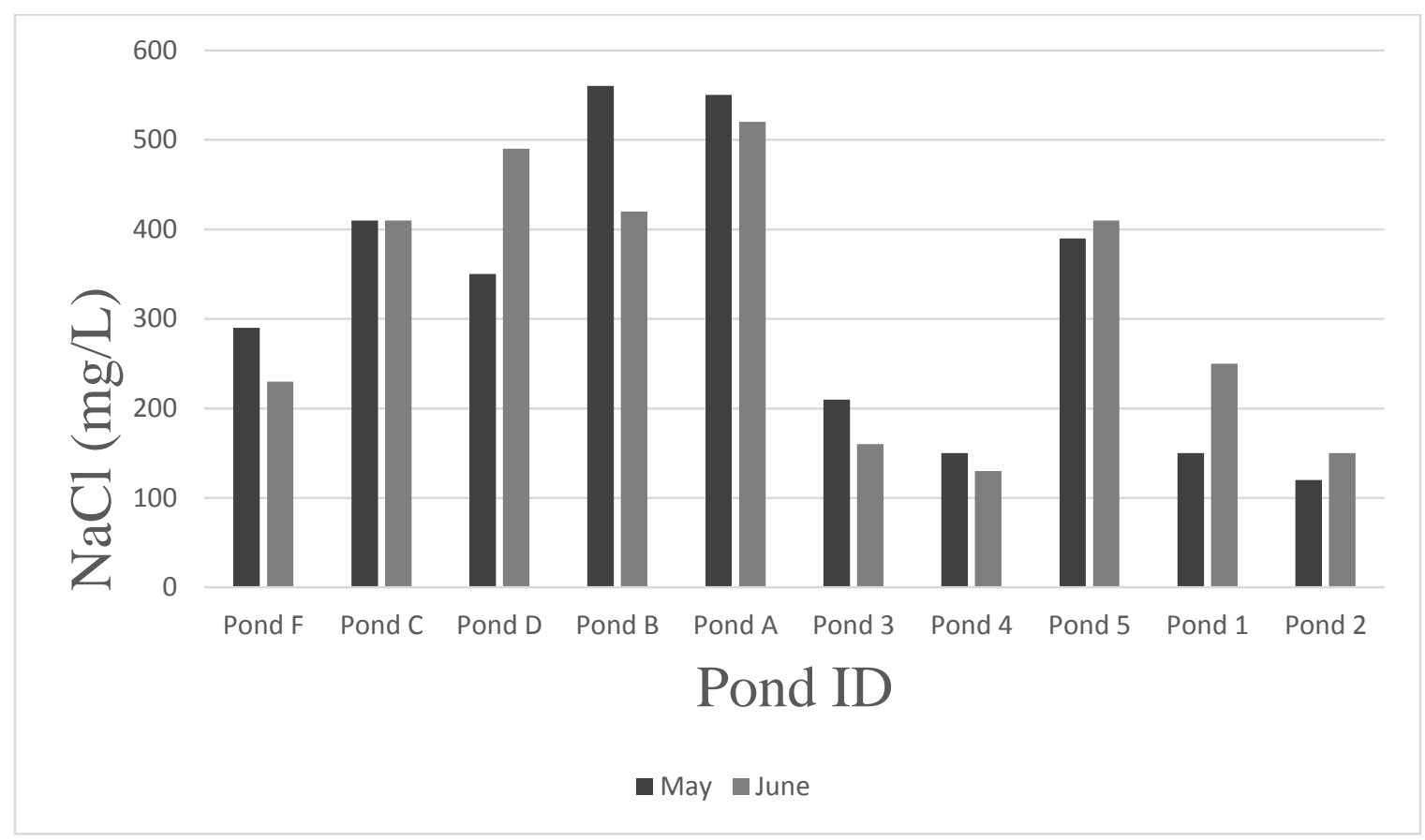


Figure 2.2: Locations of ponds for field-collected $\mathrm{NaCl}$ values in 2015 .

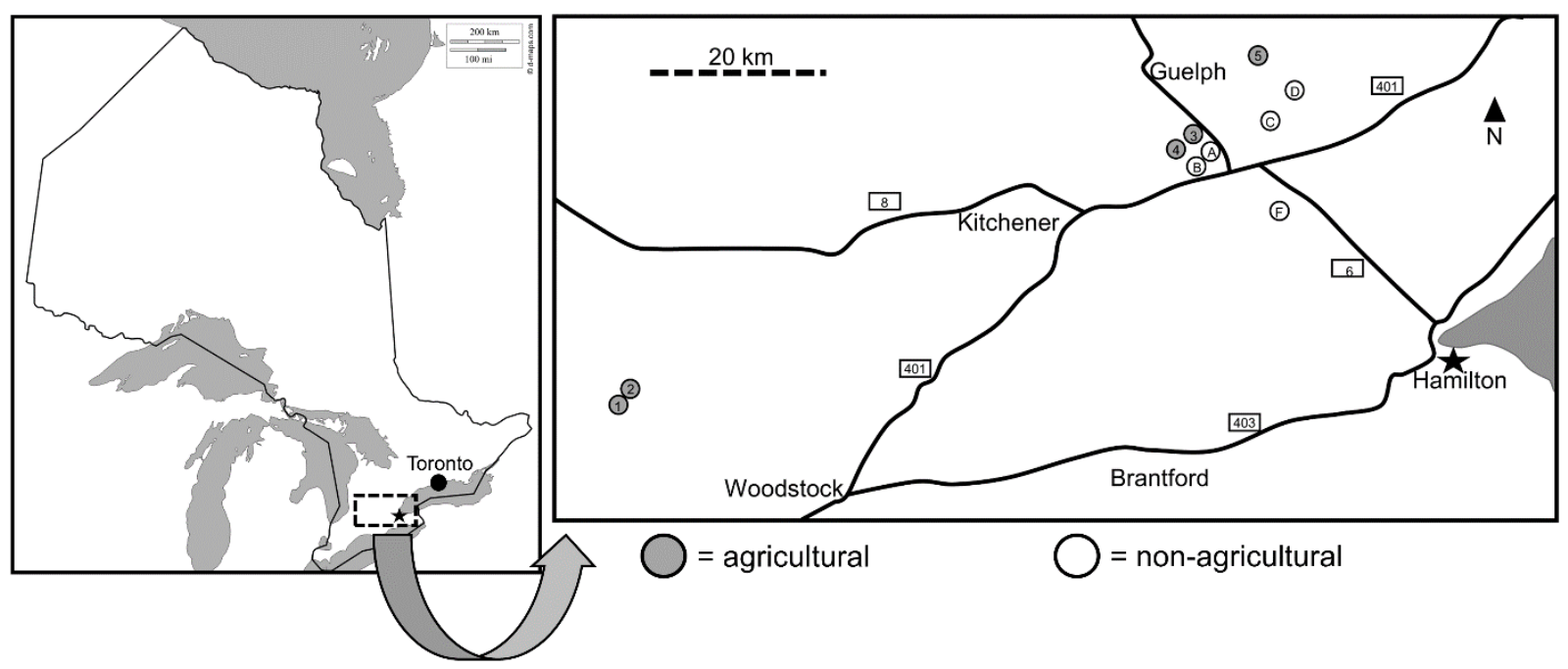


Table 2.1: Locations and surrounding agricultural activity for ten field sites. Abbreviations: ID = site identification corresponding to Figure 2.2 map (letters and numbers correspond to nonagriculture and agricultural sites, respectively), $\mathrm{CA}=$ distance to closest agricultural activity $(\mathrm{m})$, and $\mathrm{AA}=$ average distance to agricultural activity $(\mathrm{m})$, and $\mathrm{SA}=$ pond surface area $\left(\mathrm{m}^{2}\right)$. Refer to text for methodology and detailed descriptions.

\begin{tabular}{|c|c|c|c|}
\hline Pond ID & $\mathbf{C A}$ & $\mathbf{A A}$ & Site location \\
\hline $\mathrm{E}$ & 210.7 & 589 & $\begin{array}{c}43^{\circ} 30^{\prime} 47.71 " \mathrm{~N} \\
80^{\circ} 8^{\prime} 4.60^{\prime \prime} \mathrm{W}\end{array}$ \\
\hline A & 237.3 & 867.9 & $\begin{array}{l}43^{\circ} 27^{\prime} 35.05^{\prime \prime N} \\
80^{\circ} 13^{\prime} 15.06 " \mathrm{~W}\end{array}$ \\
\hline $\mathrm{B}$ & 280 & 848.3 & $\begin{array}{l}43^{\circ} 27^{\prime} 43.97^{\prime \prime N} \\
80^{\circ} 13^{\prime} 12.57^{\prime \prime W}\end{array}$ \\
\hline $\mathrm{C}$ & 104.9 & 853.8 & $\begin{array}{l}43^{\circ} 29^{\prime} 53.13 " \mathrm{~N} \\
80^{\circ} 7^{\prime} 14.60^{\prime \prime} \mathrm{W}\end{array}$ \\
\hline $\mathrm{D}$ & 222.4 & 429.6 & $\begin{array}{l}43^{\circ} 31^{\prime} 35.84^{\prime \prime N} \\
80^{\circ} 5^{\prime} 16.75^{\prime \prime} \mathrm{W}\end{array}$ \\
\hline 1 & 70 & 111.4 & $\begin{array}{c}43^{\circ} 13^{\prime} 6.47^{\prime \prime N} \\
81^{\circ} 0^{\prime} 18.07^{\prime \prime} \mathrm{W}\end{array}$ \\
\hline 2 & 24.9 & 113.1 & $\begin{array}{c}43^{\circ} 13^{\prime} 4.95^{\prime \prime} \mathrm{N} \\
81^{\circ} 0^{\prime} 15.54^{\prime \prime} \mathrm{W}\end{array}$ \\
\hline 3 & 30.4 & 79.1 & $\begin{array}{l}43^{\circ} 28^{\prime} 20.43^{\prime \prime} \mathrm{N} \\
80^{\circ} 14^{\prime} 23.11^{\prime \prime} \mathrm{W}\end{array}$ \\
\hline 5 & 13.4 & 335.4 & $\begin{array}{l}43^{\circ} 33^{\prime} 40.29 " \mathrm{~N} \\
80^{\circ} 8^{\prime} 12.15^{\prime \prime} \mathrm{W}\end{array}$ \\
\hline 4 & 37.7 & 45.5 & $\begin{array}{l}43^{\circ} 28^{\prime} 17.75^{\prime \prime} \mathrm{N} \\
80^{\circ} 14^{\prime} 26.76 " \mathrm{~W}\end{array}$ \\
\hline
\end{tabular}




\section{Experimental design}

The study consisted of three treatments that each had 20 replicates: 1) control (dechlorinated tap water), 2) medium (target concertation of $400 \mathrm{mg} / \mathrm{L}$ road salt), and 3) high (target concentration of $800 \mathrm{mg} / \mathrm{L}$ road salt). The concentrations reflected potential chronic conditions in rural and urban environments based on my field data which ranged from $120 \mathrm{mg} / \mathrm{L}$ $-560 \mathrm{mg} / \mathrm{L}$, and literature concentrations as high as $4300 \mathrm{mg} / \mathrm{L}$ in urban environments. The wood frog and northern leopard frog experiment were conducted separately and with different trematode species owing to temporal availability of both hosts and parasites. A probe (VWR Traceable ${ }^{\circledR}$ Salinity Meter and VWR Traceable ${ }^{\circledR}$ Conductance Meter) measuring both $\mathrm{NaCl}$ and conductivity was used to confirm treatment concentrations, which were made by dissolving commercially available Windsor Safe-T-Salt ${ }^{\circledR}$ in 20L water containers. The actual concentrations of $\mathrm{NaCl}$ for each treatment to be as follows: treatment $1=160 \mathrm{mg} / \mathrm{L}, 2=600 \mathrm{mg} / \mathrm{L}$, and $3=$ $1050 \mathrm{mg} / \mathrm{L}$ for wood frogs; treatment $1=270 \mathrm{mg} / \mathrm{L}, 2=580 \mathrm{mg} / \mathrm{L}$, and $3=1140 \mathrm{mg} / \mathrm{L}$ for the northern leopard frogs. Each replicate consisted of a single tadpole housed in a $1.5 \mathrm{~L}$ plastic container filled with $1 \mathrm{~L}$ of the assigned treatment solution and their placement was randomly distributed among shelves of a single rack using a random sequence generator with numbers 160. Northern leopard frog tadpoles were selected randomly such that an approximately equal number of individuals approximately Gosner developmental stage 30 were selected from each communal tub. Half of tadpoles were exposed to treatments for a total of 14 days and half for a total of 15 days, with one water change after 7 days, and were fed boiled spinach ad libitum. Wood frog tadpoles followed the same protocol but selected tadpoles were at Gosner developmental stage 35. In both experiments, behavioural recordings and infection occurred at day 12 and day 13 such that half of individuals were exposed on day 12 and half on day 13 . The 
tadpoles were euthanized two days after parasite exposure so half of the tadpoles were in treatment conditions for 14 days, and half for 15 days.

\section{Parasite exposure and behavioural recording}

The portion of the experiment carried out with wood frogs involved recording their behaviour during their exposure to cercariae. Half of the wood frog tadpoles were recorded after 12 days of treatment, and the other half after 13 days. Snails were left overnight to shed $R$. ondatrae cercariae that were then collected under a dissecting scope beginning at 7 a.m. the day of the experiment. Actively swimming cercariae were picked randomly from the snails to account for variation in cercariae age and genetic diversity and were individually pipetted into microcentrifuge tubes until each tube contained 20 cercariae. Two digital camcorders mounted on tripods were used such that five of the individual 1.5L tubs fit under each camera. The two cameras were separated by white cardboard blinds to isolate the tadpoles from their surroundings. Tubs were selected systematically according to their ID and tadpoles were kept in their treatment solutions. Once placed under the camera, 15 minutes of acclimatization was allowed before commencing recording. After the acclimatization period, 15 minutes of recording without any parasites occurred. At this time, each tub received the dosage from a single microcentrifuge tube containing 20 cercariae and 15 minutes of recording were carried out. After this recording period, each individual container was returned to its position (i.e. cercariae remained in the container). Two days after exposure to parasites, tadpoles were weighed and euthanized in a buffered solution of $1 \%$ MS-222, wood frog tadpoles were preserved in $70 \%$ ethanol, while northern leopard frog tadpoles were preserved in formalin.

For the experiment conducted with northern leopard frogs, E. trivolvis cercariae were collected by placing snails under a $60 \mathrm{~W}$ incandescent lamp in petri dishes with dechlorinated 
water and a piece of spinach to stimulate sunlight conditions. After cercariae emerged, they were also pipetted into microcentrifuge tubes such that each contained 20 cercariae. The behaviour of the northern leopard frog tadpoles was not recorded. Rather, each tadpole received a dose of 20 cercariae by adding the contents of an individual tube to its container. The elapsed time ( $48 \mathrm{~h})$ is sufficient time for metacercariae to fully form (Friend et al., 1997) and stimulate an inflammatory response to these (Martin and Conn, 1990), which is a rapid response (Morales et al., 2010). After $48 \mathrm{~h}$, tadpoles were euthanized as above and weighed before placement into a Petri dish, dorsal side facing down with the ventral side exposed upward. Scissors were used to make an incision at the point at which the tail meets the body such that the major artery was cut. Blood was collected using a standard plastic pipette and transferred onto a glass slide, following the procedure of Davis (2008), and the blood spread with another clean slide to create a smear. The slide was left to air-dry and was then fixed with methanol by immersion into a methanol solution for one minute. To visualize the blood cells, the slides were immersed into Giemsa stain for 30 seconds, and then dipped in one solution of distilled water for 10 seconds, transferred to another solution of distilled water for 10 seconds, and then left to air dry. The tadpole was placed then placed into a solution of $10 \%$ neutral buffered formalin solution for preservation.

\section{Data gathering and analysis}

During dissections, I quantified the number of cysts in each tadpole for both the wood frog and northern leopard frog experiments, and also determined the Gosner developmental stage. To count E. trivolvis cysts in $R$. pipiens, the kidneys and pronephroi were removed and put on a slide before examination with a compound microscope. Counts of $R$. ondatrae cysts in wood frogs were done by external examination. For wood frog behavioural data, I classified each tadpole as moving or not at every 20 second interval for each individual recording, converted this 
into percentage of time points active, and then arcsine squareroot-transformed the proportional data to meet the assumptions of normality. Growth for both experiments was calculated as final (mass - initial mass)/initial mass and met the assumption of normality, as did cyst counts.

Blood smears were quantified following Davis (2008) using the 1000x (oil) objective on a compound microscope to examine either 100 fields of view, or examine until 100 leukocytes were counted. I found 100 fields of view to be sufficient, not 150 as Davis (2008) suggested. Moreover, identification of specific leukocytes such as eosinophils and lymphocytes was done (Hadji-Azimi et al., 1987). Ratios of total white blood cells (WBC) to red blood cells (RBC) and each specific white blood cell to red blood cell were calculated. The ratio of white blood cells to red blood cells, lymphocytes to red blood cells, and eosinophils to red blood cells was also arcsine squareroot-transformed.

The data for the wood frog experiment was analyzed with a multivariate analysis of variance (MANOVA) using a General Linear Model (GLM) procedure because our outcome measures were not necessarily independent of one another. Treatment (salt level) was entered as a categorical fixed effect and developmental (Gosner) stage as a covariate, with number of cysts (infected and uninfected individuals both included), growth, and activity level in the presence of cercariae as the dependent variables. I also used a MANOVA for the leopard frog experiment in the same way as for the wood frog tadpoles but only growth and number of cysts were used as dependent variables. The blood profiles of the leopard frogs were examined using a separate MANOVA with treatment as the fixed factor and development stage as a covariate, and included the following dependent variables (all arcsine squareroot-transformed): ratio of WBC to RBC, ratio of eosinophils to $\mathrm{RBC}$, ratio of neutrophils to $\mathrm{RBC}$, and ratio of lymphocytes to $\mathrm{RBC}$. I also examined the relationship between number of cysts (Poisson distribution with log link function) 
and blood profiles using Generalized Linear Mixed Models (GLMM). The fixed effects were ratio of $\mathrm{WBC}$ to $\mathrm{RBC}$ and ratio of lymphocytes to $\mathrm{RBC}$, with treatment and developmental stage entered as random effects. Non-significant predictors were dropped and the model run again. All analyses were performed with SPSS 23.1.

\section{Results:}

\section{Wood frog infection and behaviour}

Fifty-five of the surviving 58 wood frog tadpoles were infected with $R$. ondatrae (95\%), with a mean $( \pm$ S.D. $)$ infection intensity of $4.36 \pm 2.5$ (range of $0-11)$. When considering the overall outcome (i.e. all 3 dependent measures), there was a marginally insignificant effect of road salt exposure on wood frogs (Wilk's $\lambda=0.812, \mathrm{~F}_{6,104}=1.902, \mathrm{P}=0.087$ ). The betweensubjects tests showed that there was no significant effect of road salts on tadpole growth $\left(\mathrm{F}_{2,54}=\right.$ 2.386, $\mathrm{P}=0.102)$, or on cyst abundance $\left(\mathrm{F}_{2,54}=1.918, \mathrm{P}=0.157\right)$, but there was a marginally insignificant effect on tadpole activity in the presence of parasites $\left(\mathrm{F}_{2,54}=2.598, \mathrm{P}=0.084\right)$. Tukey posthoc tests indicated a significant difference in tadpole growth between the control and medium salt treatments $(\mathrm{P}=0.043)$ (Figure 2.3), a marginally insignificant difference between cyst abundance between these two treatments as well $(\mathrm{P}=0.074)$ (Figure 2.4); growth was greatest in the control tadpoles and they also had the fewest cysts. With respect to the effect of road salt on tadpole activity in the presence of cercariae, there was a significant difference between the control and medium treatments $(\mathrm{P}=0.038)$, and a marginally insignificant difference between control and high treatments $(P=0.082)$; activity was lower in both the salt treatments (Figure 2.5). Using a separate univariate ANOVA, there was no difference between treatments for tadpole activity in the absence of parasites $\left(\mathrm{F}_{2,54}=0.911, \mathrm{P}=0.408\right)$. 
Figure 2.3: Mean percentage $\log _{10}$ growth $( \pm$ S. E.) of $R$. sylvatica tadpoles in road salt treatment conditions (control $=160 \mathrm{mg} / \mathrm{L}$, medium $=600 \mathrm{mg} / \mathrm{L}$, high $=1050 \mathrm{mg} / \mathrm{L}$ of road salt).

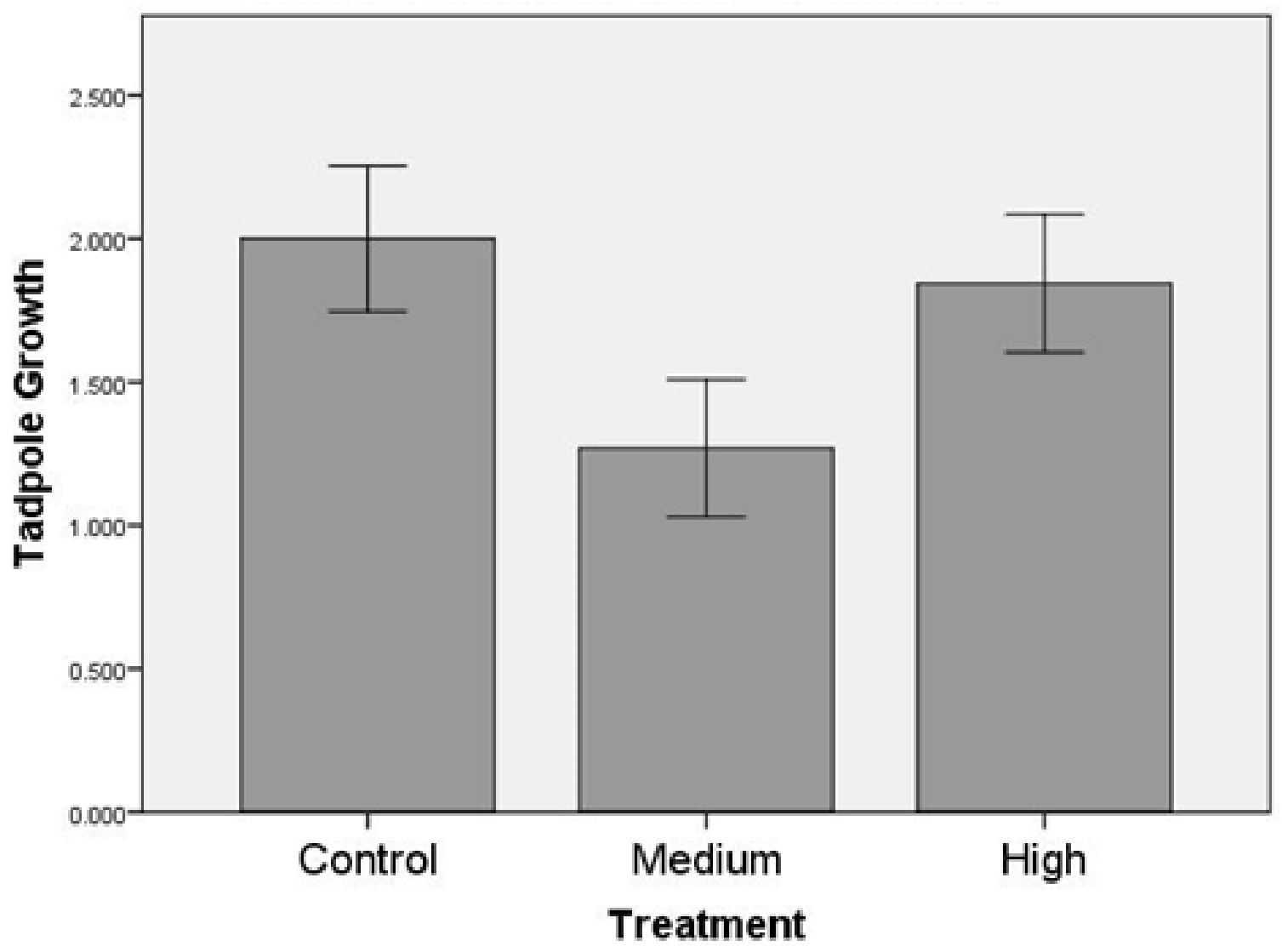

Error Bars: +/- 1 SE 
Figure 2.4: Mean ( \pm S. E.) infection intensity (\# of cysts) of $R$. ondatrae in wood frog $(R$. sylvatica) by road salt treatment conditions (control $=160 \mathrm{mg} / \mathrm{L}$, medium $=600 \mathrm{mg} / \mathrm{L}$, high $=$ $1050 \mathrm{mg} / \mathrm{L})$.

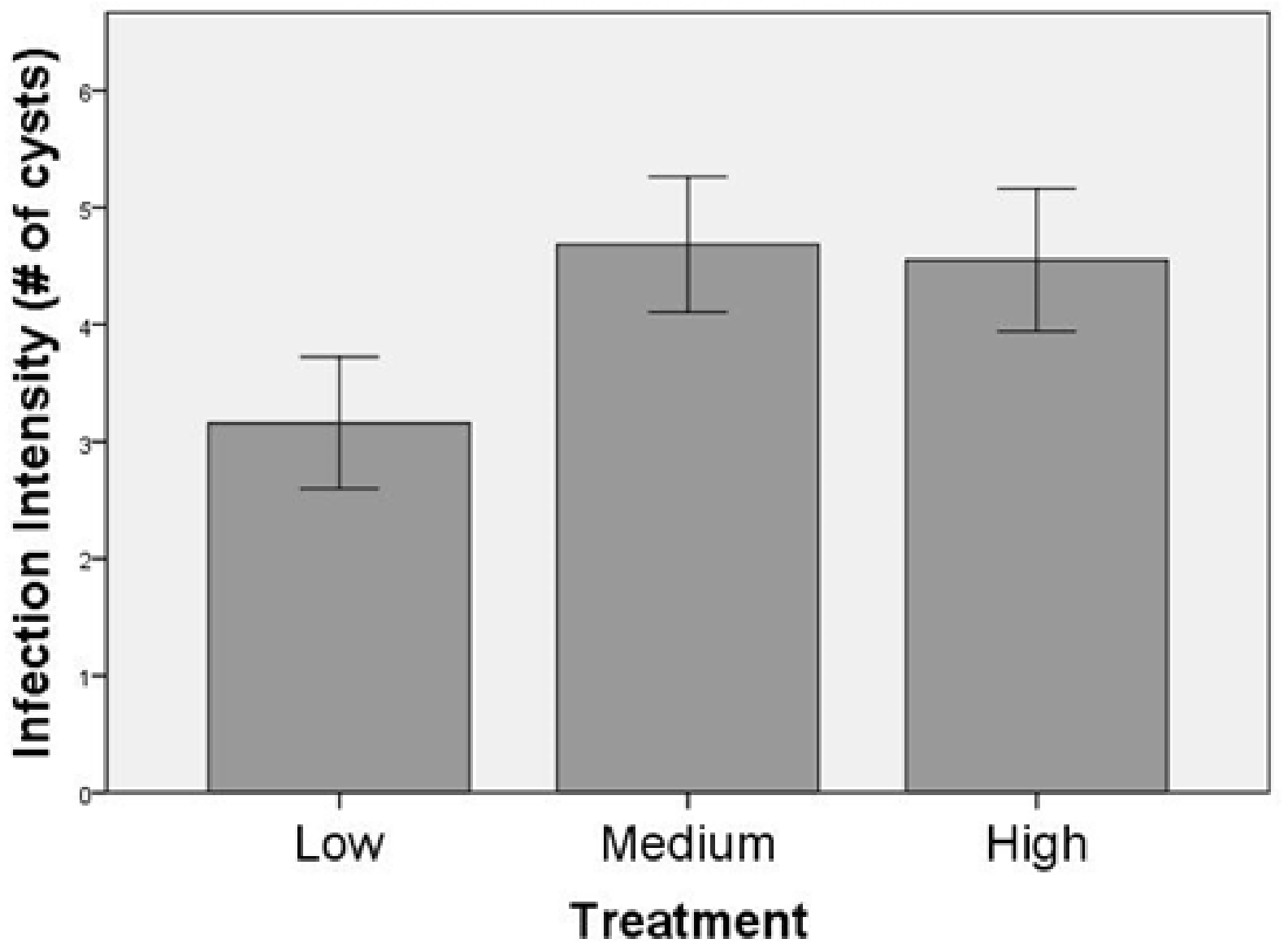

Error Bars: +/- 1 SE 
Figure 2.5: Mean proportion of time $( \pm \mathrm{S}$. E.) active for $R$. sylvatica tadpoles exposed to road salt treatment conditions $($ control $=160 \mathrm{mg} / \mathrm{L}$, medium $=600 \mathrm{mg} / \mathrm{L}$, high $=1050 \mathrm{mg} / \mathrm{L}$ ) in the presence of the trematode parasite $R$. ondatrae.

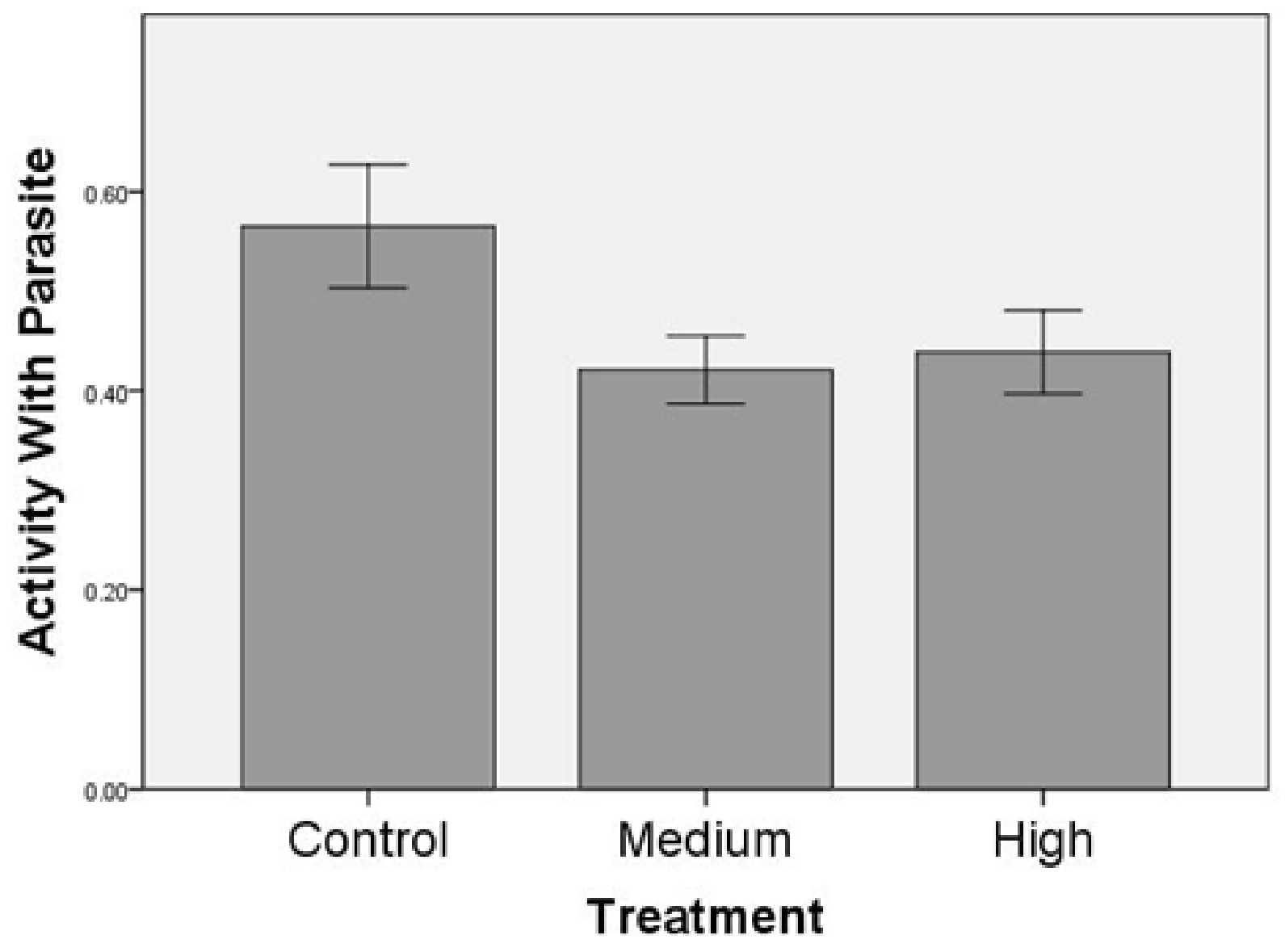

Emor Bars: +/- 1 SE 


\section{Leopard frog infection and blood profiles}

Forty-six of the surviving 56 leopard frog tadpoles were infected with E. trivolvis (82\%), with a mean $( \pm$ S.E.) infection intensity of $4.23 \pm 0.477$ (range of $0-12)$. The results of the GLM indicated that road salt had no overall effect on tadpole condition considering both growth and cyst abundance (Wilk's $\lambda=0.901, \mathrm{~F}_{4,102}=1.362, \mathrm{P}=0.252$ ). When considering the individual dependent variables, road salt had no effect on cyst abundance $\left(\mathrm{F}_{2,52}=2.206, \mathrm{P}=0.102\right)$, although posthoc tests indicated a greater number of cysts in the control than medium treatment $(\mathrm{P}=0.041)$ (Figure 2.6). There was no effect of road salt on growth $\left(\mathrm{F}_{2,52}=0.490, \mathrm{P}=0.616\right)$ (Figure 2.7). 
Figure 2.6: Mean ( \pm S. E.) E. trivolvis infection intensity (\# cysts) in R. pipiens exposed to road salt treatment conditions (control $=270 \mathrm{mg} / \mathrm{L}$, medium $=580 \mathrm{mg} / \mathrm{L}$, high $=1140 \mathrm{mg} / \mathrm{L}$ ).

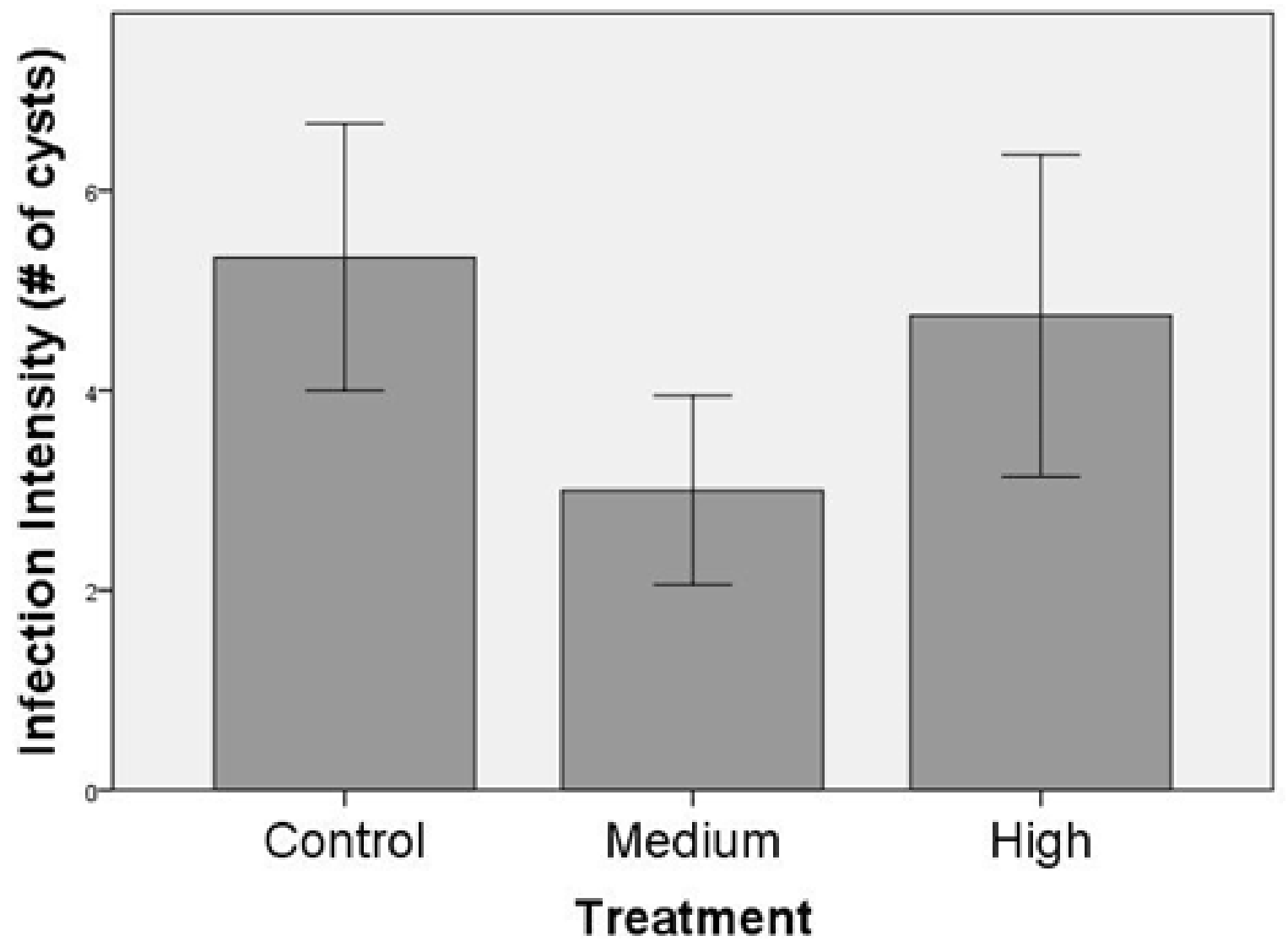

Error Bars: + + $1 \mathrm{SE}$ 
Figure 2.7: Mean $( \pm$ S. E.) proportional growth (mass change over 14 and 15 days) of northern leopard frog (R. pipiens) tadpoles in road salt treatment conditions (control $=270 \mathrm{mg} / \mathrm{L}$, medium $=580 \mathrm{mg} / \mathrm{L}$, high $=1140 \mathrm{mg} / \mathrm{L}$ ).

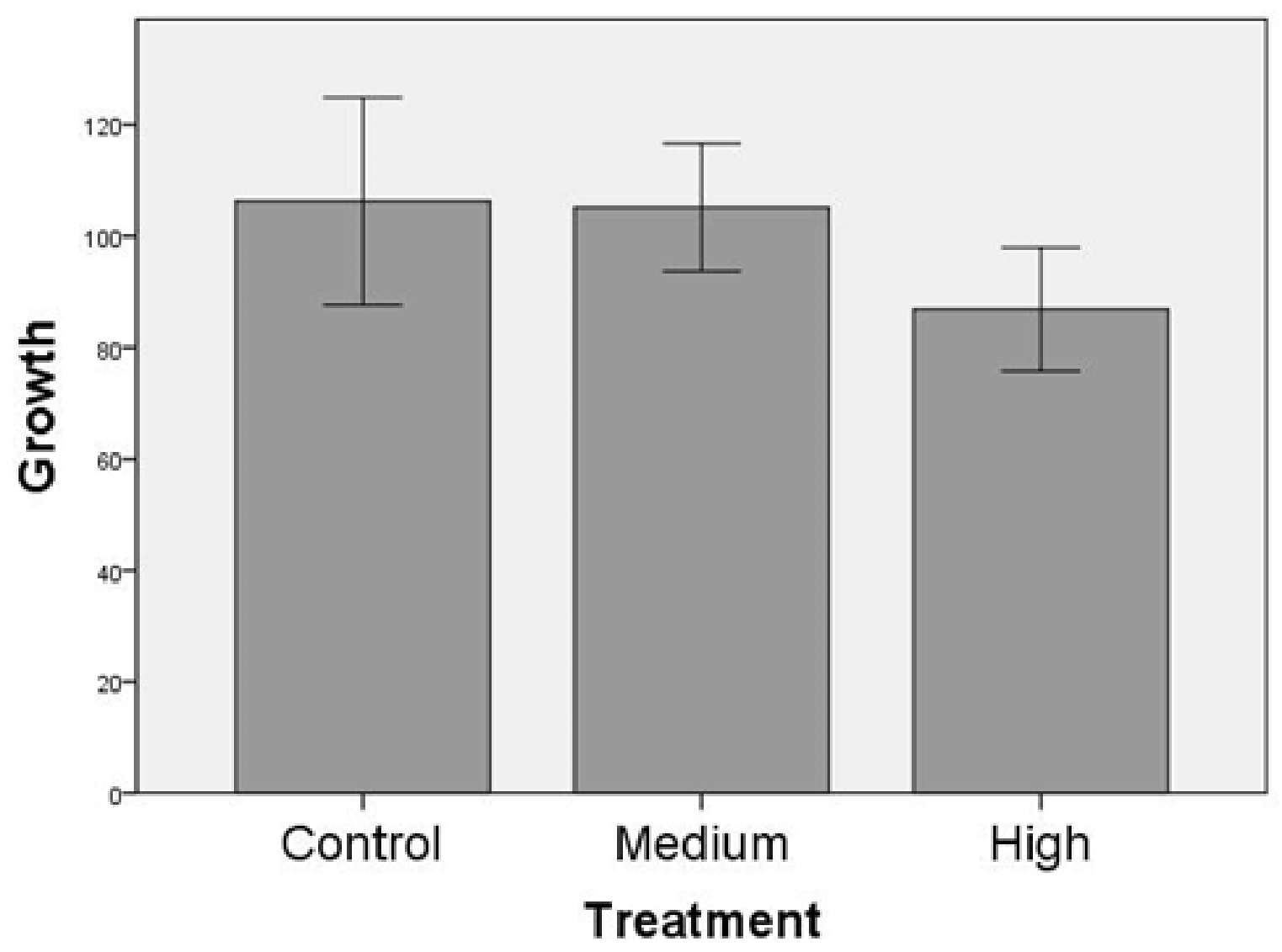

Error Bars: + $+-1 \mathrm{SE}$ 
I was able to examine blood slides from 27 tadpoles because insufficient blood was collected to make a proper blood smear for some tadpoles. The GLM for tadpole white blood cell profiles found no overall effect of treatment (Wilk's $\lambda=0.692, \mathrm{~F}_{8,38}=0.960, \mathrm{P}=0.481$ ); however, the individual between-subjects tests indicated a marginally insignificant effect on the ratio of lymphocytes to $\mathrm{RBC}\left(\mathrm{F}_{2,22}=2.863, \mathrm{P}=0.079\right)$. Posthoc tests showed significantly more lymphocytes relative to $\mathrm{RBC}$ in high vs low salt treatment $(\mathrm{P}=0.027)$, and a trend for more in medium vs low salt $(\mathrm{P}=0.091)$ (Figure 2.8). While there was no significant effect of treatment on the overall ratio of $\mathrm{WBC}$ to $\mathrm{RBC}\left(\mathrm{F}_{2,22}=1.677, \mathrm{P}=0.210\right)$, the pair-wise comparisons indicate a trend for more $\mathrm{WBC}$ relative to $\mathrm{RBC}$ in treatment 3 compared to $1(\mathrm{P}=0.085)$ (Figure 2.9). The ratio of lymphocytes to $R B C$ was not a significant predictor of cyst number $(P=0.270)$ in the initial model and was dropped, and the final model only containing the ratio of WBC to RBC was not significant either $\left(F_{1,23}=0.965, P=0.336\right)$. 
Figure 2.8: Mean $( \pm$ S. E. $)$ ratio of lymphocytes to red blood cells in R. pipiens tadpoles reared in road salt treatment conditions $($ control $=270 \mathrm{mg} / \mathrm{L}$, medium $=580 \mathrm{mg} / \mathrm{L}$, high $=1140 \mathrm{mg} / \mathrm{L}$ ) and infected by E. trivolvis.

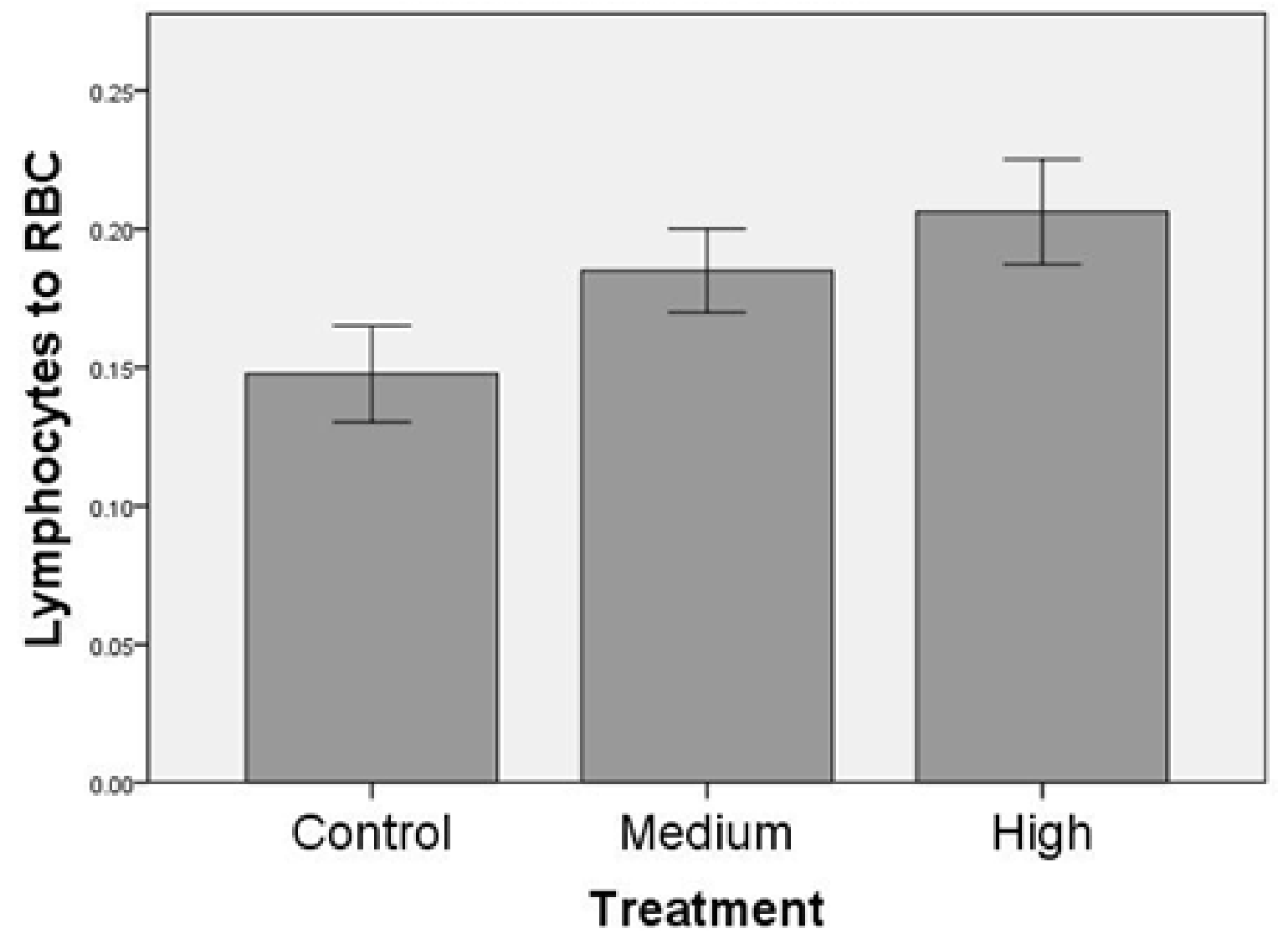

Error Bars: +1- 1 SE 
Figure 2.9: Mean $( \pm$ S. E. $)$ leukocyte to red blood cell ratio of $R$. pipiens reared in road salt treatment conditions $($ control $=270 \mathrm{mg} / \mathrm{L}$, medium $=580 \mathrm{mg} / \mathrm{L}$, high $=1140 \mathrm{mg} / \mathrm{L}$ ), infected by E. trivolvis.

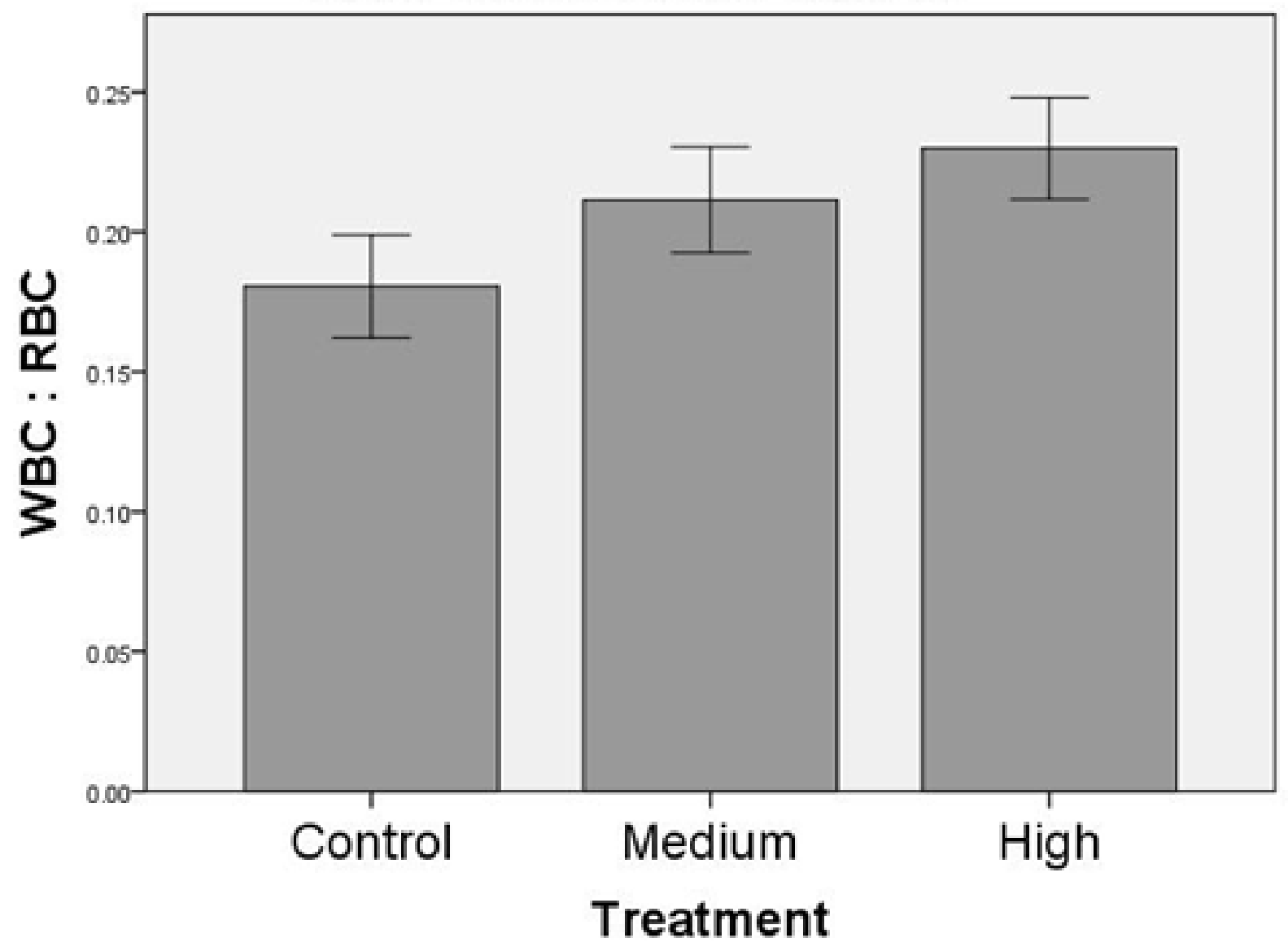

Error Bars: +/- $1 \mathrm{SE}$ 


\section{Discussion:}

Exposure of larval amphibians ( $R$. sylvatica and $R$. pipiens) to environmentally-realistic concentrations of road salts did not affect their growth, but had some influences on infection with trematode parasites, host anti-parasite activity, and host white blood cell profiles, that merit further investigation. There was no overall effect of road salts on amphibian growth but when considering pairwise comparisons, it was seen that wood frog tadpoles reared in the medium salt treatment had a significant reduction in growth compared to the control treatment. Larval amphibian growth reduction in saline conditions has been reported in literature (Findlay and Kelly, 2011; Wood and Welch, 2015), possibly because increased saline concentrations mimic a drying pool of water (Denver et al., 1998), whereby larval amphibian development is increased at the expense of mass gain to escape drying conditions in ponds (Denver, et al., 1998; Kiesecker and Skelly, 2001; Koprivnikar, et al., 2014). Reduced growth results in smaller frogs at metamorphosis that have a lower fecundity, are less competitive, and are more vulnerable to predation (Sanzo and Hecnar, 2006). This has implications for the population at large, especially if it allows other amphibian species that are not impacted by road salt to outcompete wood frogs. In this experiment, $R$. pipiens growth was not affected by road salt concentrations, suggesting this species may be more tolerant of higher salt concentrations. In addition, infection with $R$. ondatrae tends to reduce tadpole growth and increase time to metamorphosis (Johnson et al., 2012). Road salts were also found to increase mortality in tadpoles chronically exposed to elevated salinity (Sanzo and Hecnar, 2006). The LC 50 (50\% mortality) for wood frogs was found to be $\sim 4300 \mathrm{mg} / \mathrm{L}$ (Brand et al., 2010), but no effect was on mortality was seen here.

My results are consistent with findings that increased salinity will reduce growth considering the medium salt exposure; however, the lack of effect at the high salt concentration 
is not clear and might reflect a non-monotonic response, as has been seen with other contaminants such as atrazine in which higher concentrations were less detrimental than lower ones (Storrs and Kiesecker, 2004), and it warrants further study. In other studies, higher $\mathrm{NaCl}$ is more harmful to larval amphibians. For instance, as $\mathrm{NaCl}$ concentrations increased from 3,000$9,000 \mathrm{mg} / \mathrm{L}$, mortality increased until all $R$. sylvatica tadpoles died at a concentration of 9,750 $\mathrm{mg} / \mathrm{L}$ (Sanzo and Hecnar, 2006). These results followed a curve with mortality increasing as $\mathrm{NaCl}$ concentration increased. Similar results were observed in Collins and Russel (2009), where $50 \%$ of $R$. sylvatica tadpoles died at $1721.4 \mathrm{mg} / \mathrm{L}\left(\mathrm{Cl}^{-}\right)$. However, both studies used rock-salt and not commercially available road salt as in the present study.

Endocrine disruptors often affect organisms in this non-monotonic way whereby high levels of contaminants have less negative effects than medium concentrations (Lagarde et al., 2015). Alternatively, since both the parasite and larval amphibian were exposed to the same treatment conditions, it is possible that the ability of cercariae to successfully infect the host was impeded at high salt. However, further studies need to be done to disentangle the exact mechanism of why the high salt $(800 \mathrm{mg} / \mathrm{L})$ condition exhibited a non-monotonic response. Non-monotonic responses for contaminants may be explained by molecular mechanisms, whereby all of certain type of receptors' active sites are occupied by their ligands in medium concentrations such that excess of the chemical cannot produce any further effects (Lagarde et al., 2015). Similarly, larval amphibians may have a threshold level at which protein pumps are produced to mitigate osmotic stress and medium concentrations do not elicit this response, causing greater stress.

My hypothesis that road salts would increase infection rates due to stress was also consistent with the medium treatment in wood frogs, but not the high salt treatment. The 
increased activity of tadpoles in the presence of cercariae has been demonstrated to be an effective way to reduce infection by trematode parasites (Taylor et al., 2004; Koprivnikar et al., 2014), and a reduction in this anti-parasite behaviour may be the mechanism by which these tadpoles acquired more infections in the present study, i.e. by being hindered in their ability to avoid and dislodge cercariae. As a result, tadpoles in the medium salt treatment that had the lowest activity level in the presence of cercariae had the greatest number of cysts. Decreased activity by larval amphibians is consistent with previous findings that tadpoles moved slower and responded less to prodding in a salt solution (Sanzo and Hecnar, 2008; Deonël et al., 2010). In addition, I found a marginally insignificant result toward reduced activity in the high salt treatment relative to the control, and a trend for more cysts in the high salt treatment as well. However, there was no difference in activity or cyst number between the medium and high treatments. A reduction in activity may suggest that the tadpoles in treatment conditions were stressed and had lower energy reserves to employ parasite avoidance behaviour, as it has been suggested that limited energy reserves result in shifts of energy utilization away from non-vital functions (Romero, 2002).

In contrast to the wood frog results, there was a trend for greater infection by E. trivolvis in northern leopard frog tadpoles from the control solution, and this difference was significant with the medium-level salt treatment. This might be because the high variation in number of infected individuals, and therefore cysts, within the medium and high salt treatments. Interestingly, every leopard frog tadpole in the control was infected but 6/19 were not in the medium salt treatment, and 4/19 were not infected in the high salt treatment. This suggests that elevated salt levels may hinder the parasite's ability to successfully infect tadpoles. Salt may affect the ability of cercariae to locate hosts, act as a repellant to penetration if prominent in host 
tissue, impair encystment success, or it may be that the host's immune system is activated and not suppressed because of stress. Notably, both the hosts and cercariae were exposed to salt in this study. As (Pietrock and Marcogliese, 2003) explain, cercariae are fragile and environmental conditions may readily affect them. For example, temperature may increase cercarial activity but increase energy deletion, thus reducing lifespan (Pechenik and Fried, 1995; McCarthy, 1999) while other factors such as $\mathrm{pH}$ and heavy metals may increase mortality (Pietrock and Marcogliese, 2003). However, road salt affected $R$. ondatrae and not E. trivolvis cercariae in a related study of mine (see Chapter 3), suggesting there could be a hindrance to their infection success of wood frogs, and perhaps other host species, rather than increased cercariae mortality.

The pattern of higher infection intensity for leopard frog tadpoles in the control solution relative to the salt treatments might be explained by their white blood cell profiles. There was a strong trend for elevated white blood cell counts in tadpoles exposed to salt, which was especially evident for the ratio of lymphocytes to red blood cells. Vertebrates typically have five white blood cell types: monocytes, basophils, lymphocytes, neutrophils and eosinophils (Davis et al., 2008). Neutrophils and heterophils operate by phagocytosis to clear infections and respond to stimuli such as pathogens, inflammation, and stress (Belden and Kiesecker, 2005; Davis et al., 2008; LaFonte and Johnson, 2013). Lymphocytes are signalling cells that trigger immunological responses such as production of immunoglobulins and enhance the immune response (Campbell, 1995). Eosinophils are involved in inflammation processes (Jain, 1993) and attack parasitic infections (Maxwell, 1987; Rupley, 1997; Kiesecker, 2002), while monocytes play a role with infection of bacteria (Campbell, 1995; Davis et al., 2004). Enhanced numbers of all of these would presumably decrease tadpole susceptibility to parasitic infections, such as those by trematodes. Importantly, the ratios of heterophils or neutrophils to lymphocytes is an effective 
way to determine stress hormone levels (Belden and Kiesecker, 2005; Davis et al., 2008;

LaFonte and Johnson, 2013), with high ratios positively associated with glucocorticoids. Because glucocorticoids are stress hormones (Belden and Kiesecker, 2005), it is possible that salt exposure caused physiological stress to the northern leopard frog tadpoles in this study, thereby elevating their white blood cell counts and reducing susceptibility to parasitism - contrary to my expectations. However, certain limitations must be noted with blood smears. They do not reveal if lymphocytes or heterophils are found in other non-blood compartments at any given time, or the release potential of these into the blood. For example, (Cathers et al., 1997) looked at leukocyte profiles of bullfrogs (Rana catesbeiana) and found lymphocyte and neutrophil proportions to be at $63 \%$ and $22 \%$. A study looked at the same species and found $27 \%$ and $61 \%$ for the same parameters (Coppo et al., 2005). Such contrasting results suggest that there may be large fluctuations in ratios among white blood cells at any given time. However, studies involving immunosuppression as measured by white blood cell profiles are generally considered rigorous, with changes in eosinophils, neutrophil and lymphocyte counts corresponding to different infection outcomes such as increased infection in tadpoles (Bennett and Johnson, 1973; Belden and Kiesecker, 2005; LaFonte and Johnson, 2013).

Wood frog and northern leopard frog tadpoles showed different responses to road salt exposure in this study, and this might have occurred for various reasons. Firstly, species with a "fast" or "slow" pace of life invest differentially in their immune systems (Johnson et al., 2012). Slow species take longer to develop and have longer life spans, and also tend to invest more in immunological defenses (Schmid-Hempel and Ebert, 2003; Martin et al., 2006; Lee et al., 2008); in contrast, fast species are thought to invest less in immunological defenses and more into behavioural defenses (Martin et al., 2006; Lee et al., 2008; Johnson et al., 2012). Notably, wood 
frogs develop much more rapidly than northern leopard frogs (Johnson et al., 2012), which could explain why their impaired anti-parasite behaviour in the medium level of salt led to more infections, i.e. if their primary mode of avoiding infections is through behavioural means. In contrast, northern leopard frog tadpoles might invest more in immunological defences. Immunity comes at the cost of other things like growth and reproduction, and such trade-offs in fast and slow-paced species have been seen in many taxa (Martin et al., 2006; Lee et al., 2008), with the same has observed in slower species that encounter more parasites and also have greater immune investment (Schmid-Hempel and Ebert, 2003; Martin et al., 2006; Lee et al., 2008).

Unfortunately, I was not able to gather both behavioural and immunological data for either species. In addition, wood frogs often inhabit temporary ponds compared to the permanent ponds typically preferred by leopard frogs (Koprivnikar et al., 2014), and so their ability to detect variations in salinity and escape drying habitats may be better-developed such that they responded differently to elevated salt in this study.

While interspecific differences might have played a role here, the wood frog and northern leopard frog tadpoles were at different developmental stages at the time of their experimental exposures. Larval amphibians are known to be most susceptible to infections by both E. trivolvis and $R$. ondatrae at early stage of development (Schotthoefer et al., 2003; Holland et al., 2007; Johnson et al., 2011). The wood frogs used here had a mean Gosner developmental stage of 38 (presence of hind legs with toes), while the mean developmental stage of the northern leopard frog tadpoles was 28 (early limb buds) meaning that wood frogs were more resistant to trematode infection. In addition, differences between host species could be attributable to the use of two different trematode species that may have been differently affected by road salt. 
The implications of my findings are different for the two host species used. The antiparasite behaviour of $R$. sylvatica was negatively impacted by medium road salt concentrations resulting in higher infection rates. If similar results are observed in other amphibian species, then there are far-reaching implications on the susceptibility of naïve amphibian populations to infection. In contrast, $R$. pipiens experienced the greatest infection rates in the control treatment which suggests that road salt impacted a mechanism by which cercariae infect tadpoles. It is not known if the differences between $R$. sylvatica and $R$. pipiens are due to parasite species differences, behaviour, or host species. However, differential impact might lead to amphibian community in natural habitats. Conversely, if E. trivolvis ability to infect is impacted by road salts, it may lead to parasite community shifts and differential infection success. Lastly, higher concentrations of road salt must be used to explore host-parasite interactions in urban ponds, such as the $1500 \mathrm{mg} / \mathrm{L}$ documented in such sites (see Table 1.1), as well as chronic long term experiments in which tadpoles are reared in elevated salinities and then infected. Cercarial ability to infect hosts may also be examined by exposing cercariae to different salt concentrations and infecting tadpoles. 


\section{References:}

Cathers, T., Lewbart, G.A., Correa, M. \& Stevens, J.B. (1997) Serum chemistry and hematology values for anesthetized American bullfrogs (Rana catesbeiana). Journal of Zoo and Wildlife Medicine, 28, 171-174.

Coppo, J.A., Mussart, N.B., Fioranelli, S.A. \& Zeinsteger, P.A. (2005) Blood and urine physiological values in captive bullfrog, Rana catesbeiana (Anura: Ranidae). Analecta Veterinaria, 25, 15-17.

Belden, L. K., \& Kiesecker, J. M. (2005). Glucocorticosteroid hormone treatment of larval treefrogs increases infection by Alaria sp. trematode cercariae. Journal of Parasitology, 91, 686688.

Bennett, M. F., \& Johnson, A. O. (1973). Osmotic stress, ACTH and the white blood cell picture in newts, Notophthalmus viridescens. Journal of Comparative Physiology, 82, 333-338.

Brand, A. B., Snodgrass, J. W., Gallagher, M. T., Casey, R. E., \& Van Meter, R. (2010). Lethal and sublethal effects of embryonic and larval exposure of Hyla versicolor to stormwater pond sediments. Archives of Environmental Contamination and Toxicology, 58, 325-331.

Campbell, T.W. (1995) Avian Hematology and Cytology. Iowa State University Press, Ames, Iowa.

Collins, S. J., \& Russell, R. W. (2009). Toxicity of road salt to Nova Scotia amphibians. Environmental Pollution, 157, 320-324.

Dantzer, R., O'Connor, J. C., Freund, G. G., Johnson, R. W., \& Kelley, K. W. (2008). From inflammation to sickness and depression: When the immune system subjugates the brain. Nature Reviews Neuroscience, 9, 46-56. 
Daszak, P., Berger, L., Cunningham, A.A., Hyatt, A.D., Green, D.E., \& Speare, R. (1999). Emerging infectious diseases and amphibian population declines. Emerging Infectious Diseases, 5, 735-748.

Daszak, P., Cunningham, A.A., \& Hyatt, A.D. (2003). Infectious disease and amphibian population declines. Diversity and Distributions, 9, 141-150.

Davis, A. K., Maney, D. L., \& Maerz, J. C. (2008). The use of leukocyte profiles to measure stress in vertebrates: A review for ecologists. Functional Ecology, 22, 760-772.

Davis, A. K. (2009). Metamorphosis-related changes in leukocyte profiles of larval bullfrogs (Rana catesbeiana). Comparative Clinical Pathology, 18, 181-186.

Denoël, M., Bichot, M., Ficetola, G. F., Delcourt, J., Ylieff, M., Kestemont, P., \& Poncin, P. (2010). Cumulative effects of road de-icing salt on amphibian behavior. Aquatic Toxicology, 99, 275-280.

Denver, R. J., Mirhadi, N., \& Phillips, M. (1998). Adaptive plasticity in amphibian metamorphosis: Response of Scaphiopus hammondii tadpoles to habitat desiccation. Ecology, 79, 1859-1872.

Ditchkoff, S.S., Saalfeld, S.T. and Gibson, C.J., (2006). Animal behavior in urban ecosystems: modifications due to human-induced stress. Urban Ecosystems, 9, 5-12.Ducoroy, P., Lesourd, M., Padros, M.R., \& Tournefier, A. (1999). Natural and induced apoptosis during lymphocyte development in the Axolotl. Developmental and Comparative Immunology, 23, 241-25.

Freda, J., Dunson W.A., (1984). Sodium balance of amphibian larvae exposed to low environmental pH. Physiological Zoology, 57, 435-443. 
Fried, B., Pane, P.L. and Reddy, A., (1997). Experimental infection of Rana pipiens tadpoles with. Echinostoma trivolvis cercariae. Parasitology Research, 83, 666-669.Glennemeier, K. A., \& Denver, R. J. (2002). Small changes in whole body corticosterone content affect larval Rana pipiens fitness components. General and Comparative Endocrinology, 127, 16-25.

Gómez-Mestre, I., \& Tejedo, M. (2002). Geographic variation in asymmetric competition: A case study with two larval anuran species. Ecology, 83, 2102-2111.

Gomez-Mestre, I., Tejedo, M., Ramayo, E., \& Estepa, J. (2004). Developmental alterations and osmoregulatory physiology of a larval anuran under osmotic stress. Physiological and Biochemical Zoology, 77, 267-274.

Gosner, K. (1960). A Simplified Table for Staging Anuran Embryos and Larvae with Notes on Identification. Herpetologica, 16, 183-190.

Hayes, T. B., Falso, P., Gallipeau, S., \& Stice, M. (2010). The cause of global amphibian declines: A developmental endocrinologist's perspective. Journal of Experimental Biology, 213, 921-933.

Hadji-Azimi, I., Coosemans, V., \& Canicatti, C. (1987). Atlas of adult Xenopus laevis laevis hematology. Developmental and Comparative Immunology, 11, 807-874.

Hronowski, L., \& Armstrong, J. B. (1977). Ionic composition of the plasma of Ambystoma mexicanum. Comparative Biochemistry and Physiology, Part A, 58, 181-183.Jain, N.C. (1993) Essentials of Veterinary Hematology. Blackwell Publishing, Philadelphia, PA.

Barker Jørgensen, C. (1997). 200 years of amphibian water economy: From Robert Townson to the present. Biological Reviews of the Cambridge Philosophical Society, 72, 153-237.Johnson, P. T. J., Lunde, K. B., Ritchie, E. G., \& Launer, A. E. (1999). The effect of trematode infection on amphibian limb development and survivorship. Science, 284, 802-804. 
Kent, S., Bluthé, R., Kelley, K. W., \& Dantzer, R. (1992). Sickness behavior as a new target for drug development. Trends in Pharmacological Sciences, 13, 24-28.

Kiesecker, J.M. (2002) Synergism between trematode infection and pesticide exposure: a link to amphibian deformities in nature? Proceedings of the National Academy of Sciences, 99, 99009904.

King, K.C., McLaughlin, J.D., Gendron, A.D., Pauli, B.D., Giroux, I., Rondeau, B., Boily, M., Juneau, P., and Marcogliese, D.J. (2007). Impacts of agriculture on the parasite communities of northern leopard frogs (Rana pipiens) in southern Quebec, Canada. Parasitology, 134, 20632080.

King, K.C., Gendron, A.D., McLaughlin, J.D., Giroux, I., Brousseau, P., Cyr, D., Ruby, S.M., Fournier, M., and Marcogliese, D.J. (2008). Short-term seasonal changes in parasite community structure in northern leopard froglets (Rana pipiens) inhabiting agricultural wetlands. Journal of Parasitology, 94, 13-22.

Koprivnikar, J., Forbes, M. R., \& Baker, R. L. (2007). Contaminant effects on host-parasite interactions: Atrazine, frogs, and trematodes. Environmental Toxicology and Chemistry, 26, 2166-2170.

Koprivnikar, J., and Redfern, J.C. (2012). Agricultural effects on amphibian parasitism: importance of general habitat perturbations and parasite life cycles. Journal of Wildlife Diseases $48,925-936$.

Koprivnikar, J., Marcogliese, D.J., Rohr, J.R., Orlofske, S.A., Raffel, T.R. and Johnson, P.T., (2012). Macroparasite infections of amphibians: what can they tell us? EcoHealth, 9, 342-360. Koprivnikar, J., Redfern, J. C., \& Mazier, H. L. (2014). Variation in anti-parasite behaviour and infection among larval amphibian species. Oecologia, 174, 1179-1185. 
LaFonte, B. E., \& Johnson, P. T. J. (2013). Experimental infection dynamics: Using immunosuppression and in vivo parasite tracking to understand host resistance in an amphibiantrematode system. Journal of Experimental Biology, 216, 3700-3708.

Lee, K.A., Wikelski, M., Robinson, W.D., Robinson, T.R. \& Klasing, K.C. (2008). Constitutive immune defences correlate with life-history variables in tropical birds. Journal of Animal Ecology, 77, 356-363.

Ottaviani, E., and C. Franceschi. 1996. The neuroimmunology of stress from invertebrates to man. Progress in Neurobiology, 48, 421-440.

Pietrock, M., \& Marcogliese, D. J. (2003). Free-living endohelminth stages: At the mercy of environmental conditions. Trends in Parasitology, 19, 293-299.

Martin, L.B., Hasselquist, D. \& Wikelski, M. (2006). Investment in immune defense is linked to pace of life in house sparrows. Oecologia, 147, 565-575.

Mastorakos, G., Bamberger, C., \& Chrousos, G. P. (1999). Neuro endocrine regulation of the immune process. In Cytokines: Stress and immunity, N. P. Plotnikoff, R. E. Faith, A. J. Murgo, and R. A. Good (eds.). CRC Press, Boca Raton, Florida, 17-37.

Martin, T.R. and Conn, D.B., (1990). The pathogenicity, localization, and cyst structure of echinostomatid metacercariae (Trematoda) infecting the kidneys of the frogs Rana clamitans and Rana pipiens. The Journal of Parasitology, 76, 414-419.Maule, A. G., \& VanderKooi, S. P. (1999). Stress-induced immune endocrine interactions. In Stress physiology in animals, P. H. M. Balm (ed.). Sheffield Academic Press, Sheffield, U.K., 205-245.

Maxwell, M. H., \& Robertson, G. W. (1998). The avian heterophil leucocyte: a review. Worlds Poultry Science Journal, 54, 155-178. 
Meyer, M.D., Davis, C.A., and Dvorett, D. (2015). Response of wetland invertebrate communities to local and landscape factors in north central Oklahoma. Wetlands, 35, 1-14. Moore, I. T., \& Jessop, T. S. (2003). Stress, reproduction, and adrenocortical modulation in amphibians and reptiles. Hormones and Behavior, 43, 39-47.

Morales, H.D., Abramowitz, L., Gertz, J., Sowa, J., Vogel, A. and Robert, J., (2010). Innate immune responses and permissiveness to ranavirus infection of peritoneal leukocytes in the frog Xenopus laevis. Journal of virology, 84, 4912-4922.Pechenik, J. A. (1995). Effect of temperature on survival and infectivity of Echinostoma trivolvis cercariae: A test of the energy limitation hypothesis. Parasitology, 111, 373-378.

Sanzo, D., \& Hecnar, S. J. (2006). Effects of road de-icing salt ( $\mathrm{NaCl})$ on larval wood frogs (Rana sylvatica). Environmental Pollution, 140, 247-256.

Schell, S.C., 1985. Handbook of trematodes of North America north of Mexico. University Press of Idaho.

Schotthoefer, A. M., Cole, R. A., \& Beasley, V. R. (2003). Relationship of tadpole stage to location of echinostome cercariae encystment and the consequences for tadpole survival. Journal of Parasitology, 89, 475-482.

Schmid-Hempel, P., \& Ebert, D. (2003). On the evolutionary ecology of specific immune defence. Trends Ecology \& Evolution, 18, 27-32.

Semlitsch, R. D. (2000). Principles for management of aquatic-breeding amphibians. Journal of Wildlife Management, 64, 615-631.

Storrs, S. I., \& Kiesecker, J. M. (2004). Survivorship patterns of larval amphibians exposed to low concentrations of atrazine. Environmental Health Perspectives, 112, 1054-1057. Rupley, A.E. (1997) Manual of Avian Practice. W.B. Saunders Company, Philadelphia PA. 
Taylor, C. N., Oseen, K. L., \& Wassersug, R. J. (2004). On the behavioural response of Rana and Bufo tadpoles to Echinostomatoid cercariae: Implications to synergistic factors influencing trematode infections in anurans. Canadian Journal of Zoology, 82, 701-706.

Tournefier, A. (1982). Corticosteroid action of lymphocyte subpopulations and humoral immune responses of axolotl (Urodele Amphibian). Immunology, 46, 155-162.

Trudeau, V. L., Schueler, F. W., Navarro-Martin, L., Hamilton, C. K., Bulaeva, E., Bennett, A., Fletcher, W. and Taylor, L., (2013). Efficient induction of spawning of Northern leopard frogs (Lithobates pipiens) during and outside the natural breeding season. Reproductive Biology and Endocrinology, 11, 11-14.

Ultsch, G. R., Bradford, D. F., \& Freda, J. (1999). Physiology: coping with the environment. In R. W. McDiarmid and R. Altig (eds.), Tadpoles: The Biology of Anuran Larvae, University of Chicago Press, pp. 189-214.

Voyles, J., Berger, L., Young, S., Speare, R., Webb, R., Warner, J., Rudd, D., Campbell, R. and Skerratt, L.F., (2007). Electrolyte depletion and osmotic imbalance in amphibians with chytridiomycosis. Diseases of Aquatic Organisms, 77, 113-118.

Wallace, H. (1991). The development of Triturus cristatus under osmotic stress. Roux's Archives of Developmental Biology, 200, 58-60.

Wood, L., \& Welch, A. M. (2015). Assessment of interactive effects of elevated salinity and three pesticides on life history and behavior of southern toad (Anaxyrus terrestris) tadpoles. Environmental Toxicology and Chemistry, 34, 667-676. 


\section{CHAPTER 3: EFFECTS OF ROAD SALTS ON A TREMATODE PARASITE INFECTIOUS STAGE}

\section{Introduction:}

Human encroachment on previously unaltered habitats continues to increase as once pristine environments have become degraded and their ecosystems shifted away from equilibrium (Sih et al., 2004). One indirect mechanism by which human activities can harm organisms is by the introduction of contaminants into the ecosystem, such as pesticides, heavy metals, and road salts (Stuart et al., 2004; Kaushal et al., 2005; Koprivnikar et al., 2007). Some of these chemicals have been shown to increase susceptibility of larval amphibians to trematode (flatworm) parasite infection (Koprivnikar et al., 2007). However, this chapter focuses on the parasite's perspective; specifically, the potential effects of environmental contaminants on the mortality and activity of free-swimming parasite stages, such as those of trematodes. It is also important to consider the possible differential effects on various trematode species as this can drive parasite community shifts in polluted sites if they vary in their tolerance to contaminants.

Trematodes have complex life cycles that utilize multiple hosts and involve free-living infectious stages (see Chapter 1). Briefly, an infected vertebrate carries adult worms which sexually reproduce and release eggs that are excreted through the feces. The eggs hatch in an aquatic environment, forming a free living stage called miracidia, which infects aquatic snails. Asexual reproduction occurs within the aquatic snail to produce a motile stage called cercariae, which infects various second intermediate hosts depending on the species, including larval amphibians. Successful infection results in the formation of cysts (metacercariae) in specific locations in/on the second intermediate host. However, the miracidia and cercariae of trematodes are fragile and have limited energy reserves (Pietrock and Marcogliese, 2003). 
During their free-living aquatic stage, cercariae and miracidia are exposed to various environmental factors such as fluctuations in $\mathrm{pH}$, oxygen, temperature, salinity, and heavy metals that could affect their survival, activity or ability to infect hosts (see review by Pietrock and Marcogliese, 2003). Not all species of trematodes will have equal phenotypic plasticity so a differential response curve to environmental conditions may be exhibited, thus it is important to consider pollutants that may drive community shifts. For example, the survival of some species may be negatively affected by certain pollutants while other species tolerate the conditions, giving advantage to tolerant species. Since cercariae have limited energy reserves, factors that contribute to accelerated depletion through either activity or physiology may impact the likelihood of encountering a host. The ability to infect a host may be affected by certain pollutants such that host penetration, host finding, encystment or host attachment may be hindered. Pietrock and Marcogliese, (2003) outline general effects of contaminants on various parasite species that utilize motile stages, most of which are detrimental to parasites.

The effects of salinity on cercariae have been mostly limited to studies with marine trematodes. For instance, $\mathrm{pH}$, salinity and temperature negatively affect marine cercariae activity and survival (Pietrock and Marcogliese, 2003; Koprivnikar et al., 2010), and can reduce infections in downstream hosts. In contrast, increased activity through stimulation by contaminants may result in greater contact with the host, thus increasing transmission. Salinity may also combine with other stressors such as warmer temperatures to become detrimental by reducing activity and longevity (Koprivnikar et al., 2010). In other studies, salinity affected cercariae production, encystment, and overall parasite success (Lei and Poulin, 2011; Studer and Poulin, 2012; 2013), while the intertidal trematode Maritrema novaezealandensis was found to be sensitive to UV and temperature fluctuations as well (Studer and Poulin, 2013). 
A freshwater system is considered saline if soluble salt concentrations reach 3,000 10,000 mg/L (see review by Hart, et al., 1999). However, an aquatic ecosystem is considered freshwater if the concentration of $\mathrm{NaCl}$ is below $500 \mathrm{mg} / \mathrm{L}$ (Canadian Council of Ministers of the Environment, 2011). As such, the treatment concentrations used in this experiment (control, 200, 400,600 , and $800 \mathrm{mg} / \mathrm{L}$ ) pose a low salinity environment when considering total dissolved solutes, but the values of 600 and $800 \mathrm{mg} / \mathrm{L}$ pose a saline environment in terms of $\mathrm{NaCl}$. However, information about salinity effects on freshwater parasites specific to $\mathrm{NaCl}$ is limited to a handful of studies. For example, egg hatching in a freshwater tapeworm, Schistocephalus solidus, was reduced under conditions considered saline (above $20 \mathrm{ppt} \mathrm{NaCl}$ ) for this system (Simmonds and Barber, 2016). In contrast, Petasiger nitidus, a freshwater trematode, was found to tolerate high salinity conditions $(2,900 \mathrm{~g} / \mathrm{L} \mathrm{NaCl})$ (Shostak, 1993). The infectious stages of Bolbophorus confuses, a freshwater trematode, had higher survival with increases in salinity of up to $2,500 \mathrm{mg} / \mathrm{L} \mathrm{NaCl}$ (Venable et al., 2000). These findings suggest that trematodes may exhibit phenotypic plasticity to tolerate conditions considered saline for a freshwater system, but no extensive research has been done to determine exactly which salinity levels may be detrimental.

The high usage of road salts in Canada makes leaching into freshwater environments a problem, and elevated salinities have been observed in many instances (Environment Canada, 2001; Findlay and Kelly, 2006; Deonël et al., 2010). It has been found that natural ponds experience elevated salinity in areas of high road salt use, with greater increases in salinity observed in urban environments relative to rural ponds (see Table 1.1 in Chapter 1). Furthermore, I found naturally occurring concentrations in 10 ponds located in the vicinity of Guelph, ON to be $123-560 \mathrm{mg} / \mathrm{L}$, consistent with literature findings (Chapter 2) (Environment 
Canada 2001; Daley et al., 2009; Todd and Kaltencker, 2012). Elevated salinity can affect the intermediate hosts, such as reducing host resistance and/or tolerance to parasites (see Chapter 2), but it is important to examine the possible effects on the parasites themselves, particularly freeliving stages such as the cercariae of trematodes.

Two trematode species are of particular interest, Ribeiroia ondatrae and Echinostoma trivolvis, as these can be particularly virulent and may contribute to amphibian population declines (Hayes, 2010). R. ondatrae causes limb deformities in infected amphibians (Stopper et al., 2002), while E. trivolvis encysts in the kidneys and hinders renal function (Schotthoefer et al., 2003; Holland et al., 2007). It was essential to consider the effects of road salt on these trematode species as the cercariae were exposed to the same treatment condition during the infection phase of Chapter 2. Considering the effects of road salts on these cercariae may better explain host-parasite interactions.

\section{Materials and methods:}

\section{Parasite acquisition}

The snails gathered for Chapter 2 were used for this experiment - please refer to methods detailed there regarding collection, maintenance, and screening for infected hosts. For this experiment, I used four different trematode species: Echinostoma trivolvis, Ribeiroia ondatrae, an unidentified strigeid-type cercariae, and an unidentified armatae-type cercariae. When needed, cercariae were obtained by placing infected snails in Petri dishes of water under a lamp for one hour during mid-day, with the exception of $R$. ondatrae which emerges at night - those cercariae were acquired by placing the snails in Petri dishes late in the day and collected the next morning. The cercariae were removed from Petri dishes using a dissection scope and a standard plastic pipette. After mixing cercariae of a given species in a common Petri dish to randomize variation 
in age and genotype, they were transferred into single wells of a 96 well tissue culture plate (i.e. on cercariae/well).

\section{Experimental design and procedure}

I had 5 different salinity treatments: control (no salt added), 200, 400, 600 and $800 \mathrm{mg} / \mathrm{L}$ of road salt. Considering literature values as high as $4300 \mathrm{mg} / \mathrm{L}$, and field findings as low as 123 $\mathrm{mg} / \mathrm{L}$, these treatment values were selected to reflect chronic conditions in rural and urban environments. The road salt brand used was Windsor T®. The solutions were made by dissolving road salt into dechlorinated water and checking it with a VWR Traceable ${ }^{\circledR}$ Salinity probe until the desired concentration was reached (note that the control actually had a $160 \mathrm{mg} / \mathrm{L}$ $\mathrm{NaCl}$ reading). Each treatment had 5 plates assigned to it, and each plate had 5 wells containing cercariae such that the sample size per treatment was 25 cercariae. The 4 species of trematode were examined on different days but used the same procedure. I recorded the activity (yes or no) and mortality (alive or dead) of each cercariae every 2 hours until the 8 hour mark, followed by a last time point 24 hours after commencing exposure to treatment.

\section{Data analysis}

Because my outcomes (activity and mortality) were binary and I took repeated measurements through time, the data were analyzed with a repeated-measures analysis of variance (ANOVA) using a binomial distribution and logit link function. I analyzed the effects of treatment, time, and their interaction separately for activity and mortality, including plate and well number as random factors. Each species was analyzed separately. All analyses were conducted with SPSS 23.0 using the Generalized Linear Mixed Model (GLMM) procedure. Nonsignificant interactions and fixed effects were dropped and models re-run to obtain a final model. 


\section{Results:}

Mortality

Salt treatment had no effect on the mortality of the strigeid-type cercariae $(\mathrm{P}=0.786)$, and the final model containing time was not significant $\left(\mathrm{F}_{4,546}=0.666, \mathrm{P}=0.616\right)$. In contrast, the mortality of the armatae-type cercariae was increased by treatment (overall model: $\mathrm{F}_{4,576}=$ $3.516, \mathrm{P}=0.008)$, and there was a marginally-insignificant effect of time $(\mathrm{P}=0.093)$ as survival tended to decrease with hour (Figure 3.1). However, pair-wise posthoc tests indicated no specific differences in mortality between treatments. Exposure to salt did not affect the survival of $R$. ondatrae cercariae $(\mathrm{P}=0.197)$, but mortality increased with time $\left(\mathrm{F}_{4,586}=5.831, \mathrm{P}<0.001\right)$ (Figure 3.2). Similarly, treatment did not affect mortality of E. trivolvis $(\mathrm{P}=0.812)$, nor did time $(\mathrm{P}=0.297)$. There was no significant interaction of treatment and time on the mortality of any type of cercariae. 
Figure 3.1: The number of armatae-type cercariae alive at each time point in road salt treatment conditions.

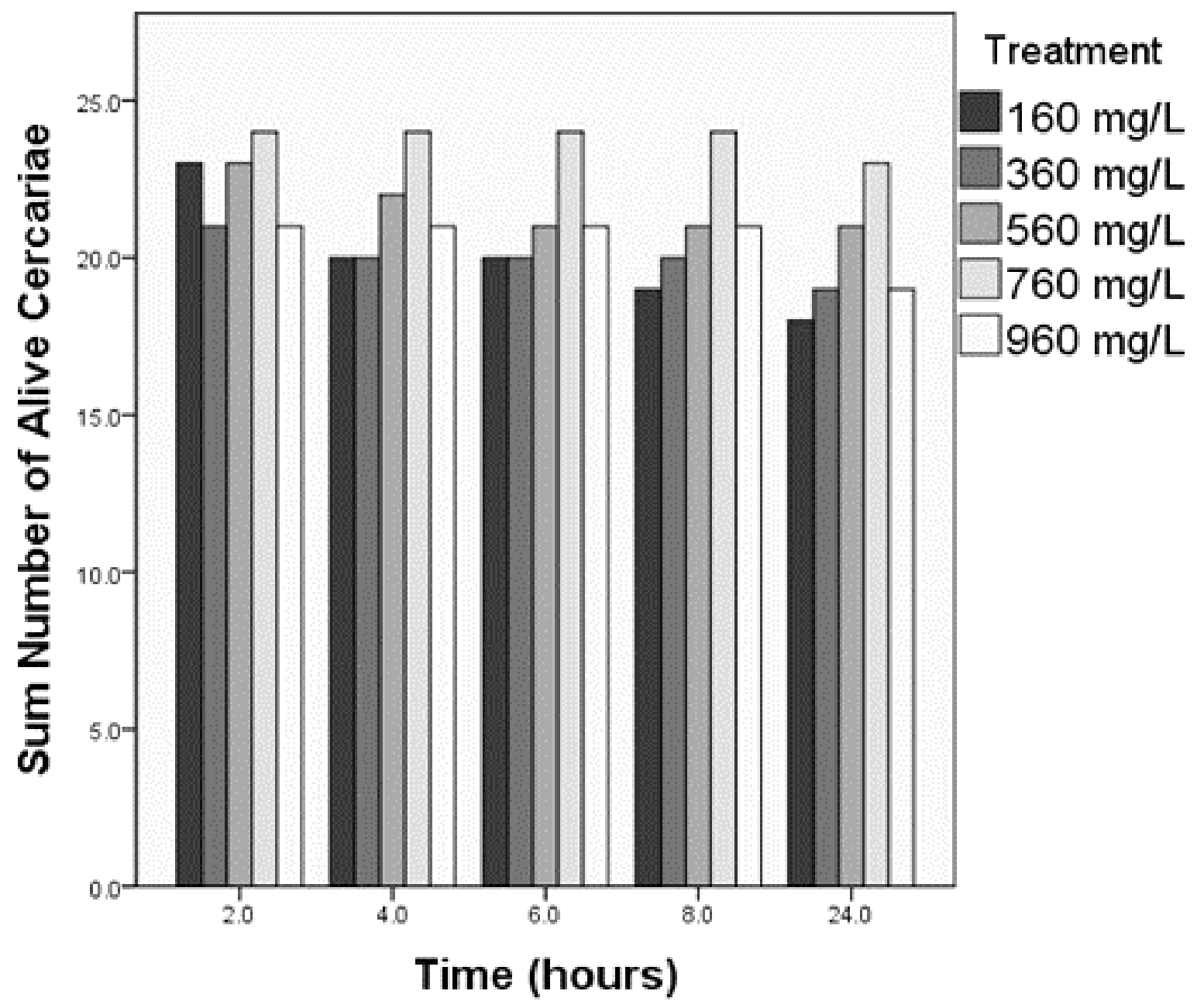


Figure 3.2: The number of $R$. ondatrae cercariae alive at each time point in road salt treatment conditions.

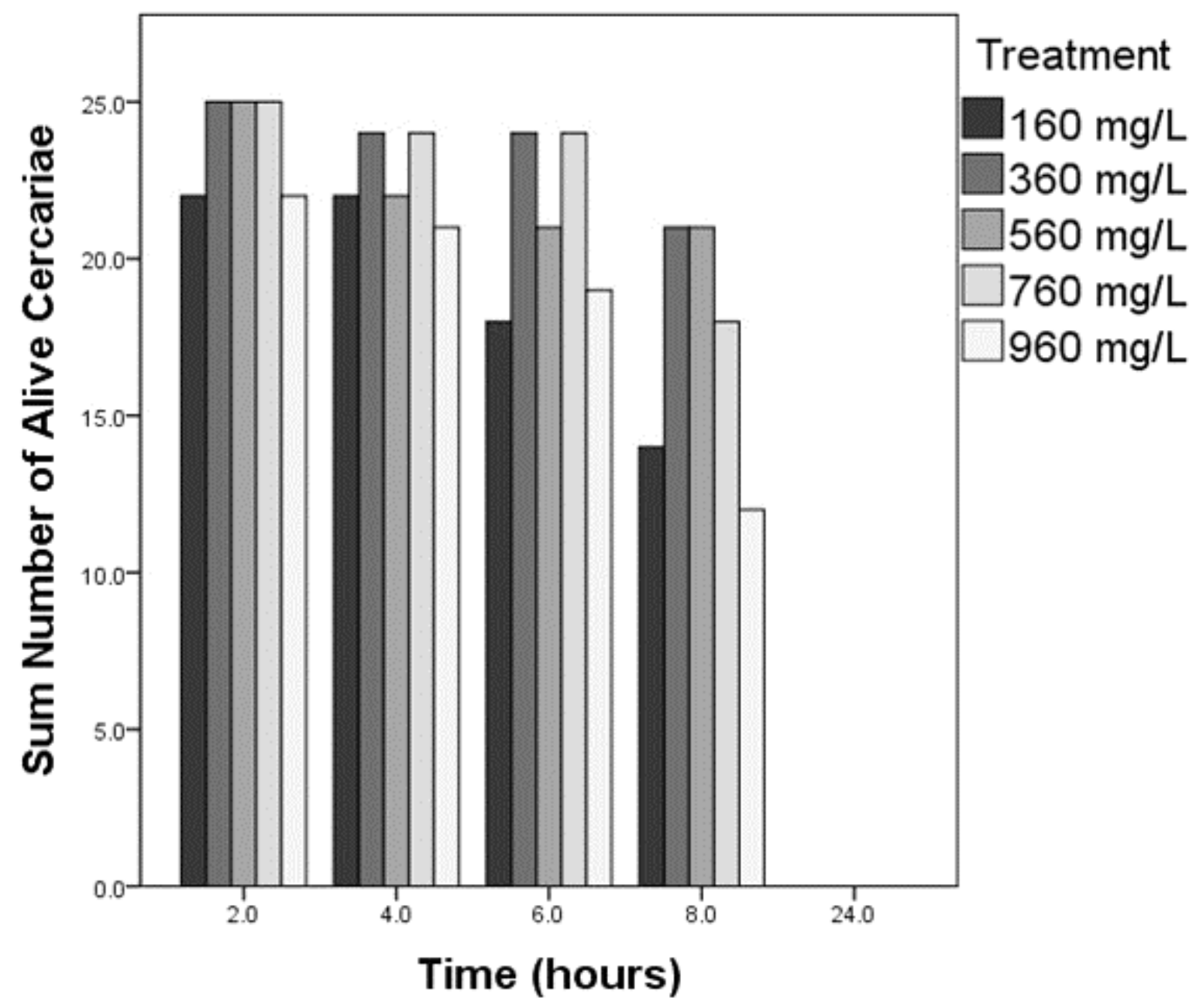




\section{Activity}

The final model for activity of the strigeid-type cercariae was significant $\left(\mathrm{F}_{8,546}=3.982\right.$, $\mathrm{P}<0.001)$ and contained treatment $(\mathrm{P}<0.001)$ and time $(\mathrm{P}=0.011)$. Activity decreased over time, and there were significant differences between the following treatments: control and 600 $\mathrm{mg} / \mathrm{L}(\mathrm{P}=0.005), 200$ and $600 \mathrm{mg} / \mathrm{L}(\mathrm{P}=0.002), 400$ and $600 \mathrm{mg} / \mathrm{L}(\mathrm{P}=0.028)$, and 600 and $800 \mathrm{mg} / \mathrm{L}(\mathrm{P}=0.014)$ (Figure 3.3). Again, the armatae-type cercariae showed a different pattern, with no effect of treatment $(\mathrm{P}=0.440)$ or time $(\mathrm{P}=0.808)$. The overall model for the activity of R. ondatrae cercariae was significant $\left(\mathrm{F}_{8,586}=10.473, \mathrm{P}<0.001\right)$ and contained treatment $(\mathrm{P}=$ $0.047)$ and time $(\mathrm{P}<0.001)$ as activity decreased with time and greater salt concentrations (Figure 3.4). However, pair-wise posthoc tests indicated no significant difference in activity between specific treatments. For E. trivolvis, salt treatment had no effect on cercariae activity (P $=0.452)$, but there was a significant effect of time $(\mathrm{P}=0.038)$. There was no significant interaction of treatment and time on the activity of any type of cercariae. 
Figure 3.3: The number of strigeid-type cercariae active at each time point in road salt treatment conditions.

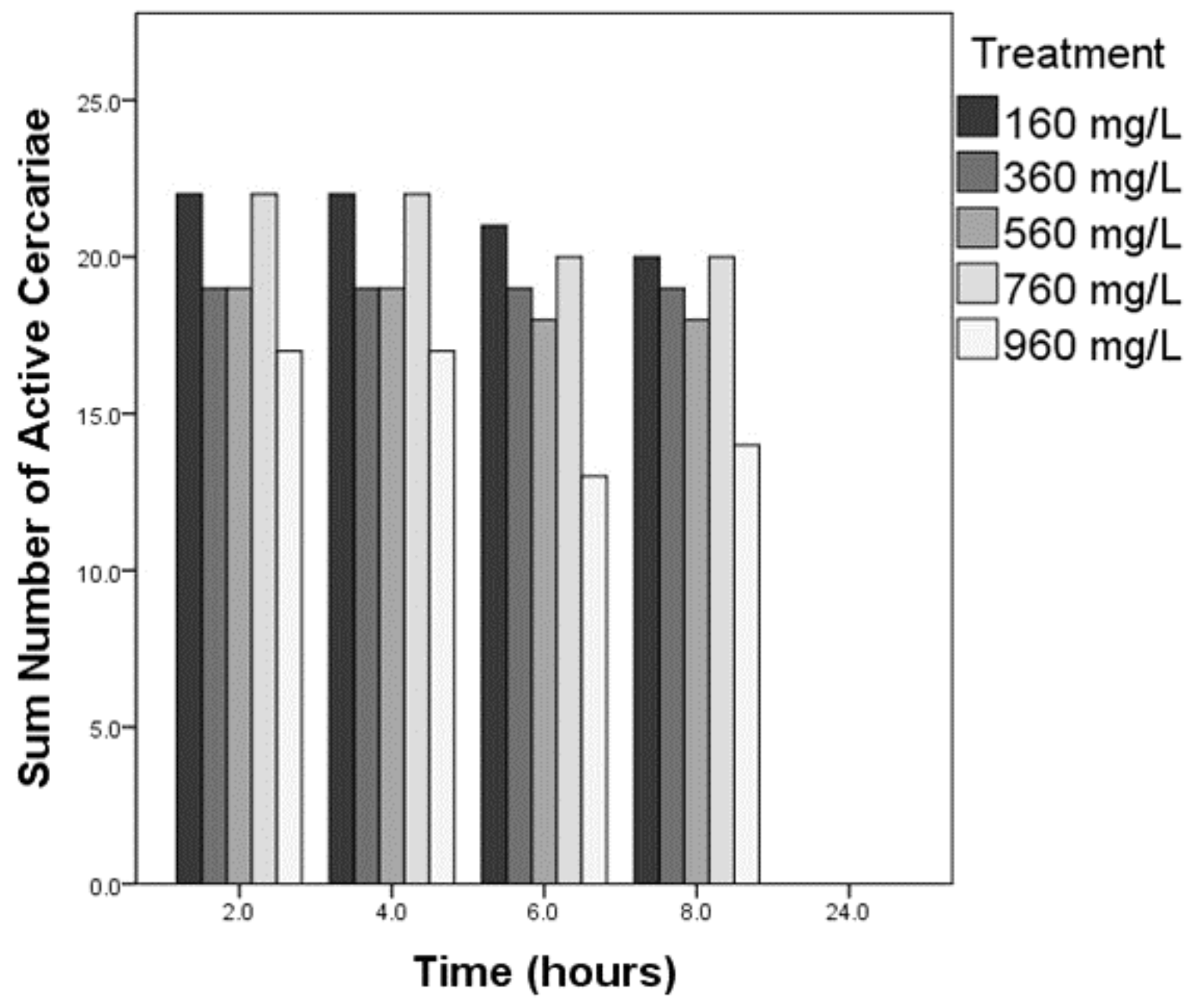


Figure 3.4: The number of $R$. ondatrae cercariae active at each time point in road salt treatment conditions

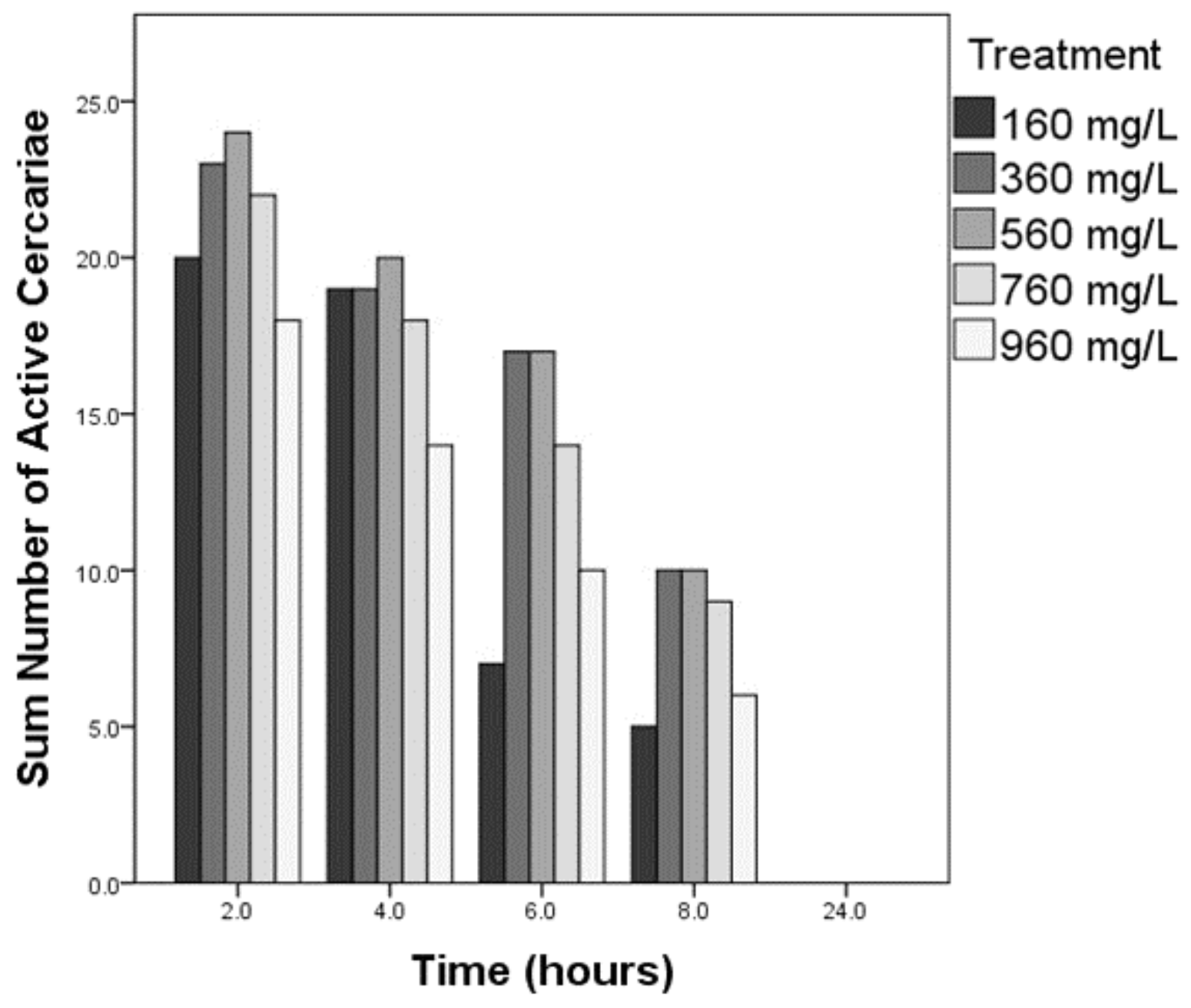




\section{Discussion:}

Trematode parasites are major constituents of ecosystems, comprising significant biomass and can serve as energy sources for other organisms (Lambden and Johnson, 2013; Preston et al., 2013). It has been suggested that the presence of parasites in an ecosystem indicates robustness and general ecosystem health owing to intact trophic links and diverse host communities (Hudson et al., 2006). As such, it is important to consider various factors that may affect parasite communities at large. It is known that salinity, temperature, UV radiation and pesticides like atrazine may negatively affect cercariae (Koprivnikar et al., 2006; Studer and Poulin, 2013). However, nothing was known regarding road salts effects on the common freshwater trematodes studied here: $R$. ondatrae, E. trivolvis, a strigeid-type cercaria, and an armatae-type cercaria. In fact, very few studies examined the effects of road salt or salinity on free swimming stages of freshwater trematodes.

In my experiment, I found that different trematodes are differentially affected by road salts. Considering mortality, armatae-type cercariae and $R$. ondatrae experienced a significant increase in mortality in treatment conditions of high road salt $(960 \mathrm{mg} / \mathrm{L})$, while that of strigeidtype cercariae and E. trivolvis was not significantly affected. $R$. ondatrae and E. trivolvis are of particular interest because they infect larval amphibians and can be particularly virulent in high concentrations (Haynes et al., 2010). As such, differential responses to road salt by these two types of cercariae is interesting because in high salt ponds, $R$. ondatrae may experience reduced success while E. trivolvis might not.

In terms of activity, strigeid-type cercariae and $R$. ondatrae experienced a reduction in activity in higher salt concentrations, while armatae-type cercariae and E. trivolvis activity was not affected by increased salinity. Generally, moderate salinity seemed to provide a benefit for $R$. 
ondatrae and armatae-type cercariae as cercariae seemed to experience the lowest mortality and activity reduction for $R$. ondatrae and lowest mortality for armatae-type cercariae in 360 and 560 $\mathrm{mg} / \mathrm{L}$ road salt treatment conditions. A mechanism by which this may occur is a reduction of osmotic stress by creating an isotonic solution in medium salt levels. Trematodes likely have some ability to tolerate salinities. For instance, the plasma of Litoria caerulea (Australian green tree frog) is as high as $102.8 \mathrm{mmol} / \mathrm{L} \mathrm{of}^{+}$and $79 \mathrm{mmol} / \mathrm{L}$ of $\mathrm{Cl}^{-}$while its osmolality was found to be $217.2 \mathrm{mmol} / \mathrm{L}$ (Voyles, et al., 2007), and can be The total tissue content of $\mathrm{Na}^{+}$has been reported as $1365-1815$ micromolar/g for Rana pipiens while $\mathrm{Cl}^{-}$is $300-825$ micromole/L in Rana sylvatica (Freda and Dunson, 1984). This suggests that salinity higher than that in freshwater would be encountered in most hosts, and suggests an inherent phenotypic plasticity and salinity tolerance in cercariae. In contrast, both mortality and activity in $R$. ondatrae was negatively impacted by the highest road salt concentration $(960 \mathrm{mg} / \mathrm{L})$. A reduction in longevity and activity of a motile life stage of a parasite may greatly affect its transmission (McCarthy, 1999), and future studies employing even higher salt concentrations, or combining salt exposure with other stressors such as elevated temperature, will be needed to more fully explore the potential effects on road salts on free-swimming parasite stages. In addition, the infectivity (ability to infect hosts) of the cercariae was not examined here. This might be compromised due to salt exposure even if mortality and/or activity are not affected.

Road salt is a problem as it is found in nature, elevating the salinity of freshwater system where it can be detrimental to the not only to ecosystem processes (Findlay and Kelly, 2011) but also to organisms living there (Sanzo and Hecnar, 2006; Findlay and Kelly, 2011). Host-parasite interaction studies are essential to determine how environmental contaminants may affect the outcome of the complex interplay between parasites and their hosts. In particular, amphibians 
group are experiencing worldwide declines (Daszak et al., 1999) and infectious disease have been implicated (Hayes et al., 2010). Information on the effects of road salt on freshwater cercariae is lacking and such research fills a gap in knowledge which may aid researchers to comprehensively determine mechanisms by which road salts may act on amphibian host-parasite systems. 


\section{References:}

Canadian Council of Ministers of the Environment. (2011). Canadian water quality guidelines for the protection of aquatic life: Chloride. In: Canadian environmental quality guidelines, 1999, Canadian Council of Ministers of the Environment, Winnipeg.

Daley, M. L., Potter, J. D., \& McDowell, W. H. (2009). Salinization of urbanizing New Hampshire streams and groundwater: Effects of road salt and hydrologic variability. Journal of the North American Benthological Society, 28, 929-940.

Daszak, P., Berger, L., Cunningham, A. A., Hyatt, A. D., Green, D. E., \& Speare, R., (1999). Emerging infectious diseases and amphibian population declines. Emerging Infectious Diseases, 5, 735-748.

Denoël, M., Bichot, M., Ficetola, G. F., Delcourt, J., Ylieff, M., Kestemont, P., \& Poncin, P. (2010). Cumulative effects of road de-icing salt on amphibian behavior. Aquatic Toxicology, 99, 275-280.

Environment Canada, (2001). Environment Canada, Priority substance list Assessment Report Road Salts, Environment Canada, Ottawa, Canada. http://www.hc-sc.gc.ca/ewhsemt/pubs/contaminants/ps12-1sp2/road_salt_sels_voirie/index-eng.php

Findlay, S. E. G., \& Kelly, V. R. (2011). Emerging indirect and long-term road salt effects on ecosystems. Annals of New York Academy of Sciences, 1223, 58-68.

Freda, J., Dunson W.A., (1984). Sodium balance of amphibian larvae exposed to low environmental pH. Physiological Zoology, 57, 435-443.

Hart BT, Bailey P, Edwards R, Hortle K, James K, McMahon A, Meredith C, Swadling K (1991). A review of the salt sensitivity of the Australian freshwater biota. Hydrobiologia, 210, $105-144$. 
Hayes, T. B., Falso, P., Gallipeau, S., \& Stice, M. (2010). The cause of global amphibian declines: A developmental endocrinologist's perspective. Journal of Experimental Biology, 213, 921-933.

Holland, M. P., Skelly, D. K., Kashgarian, M., Bolden, S. R., Harrison, L. M., \& Cappello, M. (2007). Echinostome infection in green frogs (Rana clamitans) is stage and age dependent, Journal of Zoology, 271, 455-462.

Hudson, P. J., Dobson, A. P., \& Lafferty, K. D. (2006). Is a healthy ecosystem one that is rich in parasites? Trends in Ecology and Evolution, 21, 381-385.

Johnson, P. T. J., Lunde, K. B., Ritchie, E. G., \& Launer, A. E. (1999). The effect of trematode infection on amphibian limb development and survivorship. Science, 284, 802-804.

Kaushal, S. S., Groffman, P. M., Likens, G. E., Belt, K. T., Stack, W. P., Kelly, V. R., Band, L.E., \& Fisher, G. T. (2005). Increased salinization of fresh water in the northeastern United States. Proceedings of the National Academy of Sciences of the United States of America, 102, 13517-13520.

Koprivnikar, J., Forbes, M. R., \& Baker, R. L. (2006). Effects of atrazine on cercarial longevity, activity, and infectivity. Journal of Parasitology, 92, 306-311.

Koprivnikar, J., Forbes, M. R., \& Baker, R. L. (2007). Contaminant effects on host-parasite interactions: atrazine, frogs and trematodes. Environmental Toxicology and Chemistry, 26, 21662170.

Koprivnikar, J., D. Lim, C. Fu, and S. H. M. Brack. (2010) Effects of temperature, salinity, and $\mathrm{pH}$ on the survival and activity of marine cercariae. Parasitology Research, 106: 1167-1177. Lambden, J., \& Johnson, P. T. J. (2013). Quantifying the biomass of parasites to understand their role in aquatic communities. Ecology and Evolution, 3, 2310-2321. 
Lei, F., \& Poulin, R. (2011). Effects of salinity on multiplication and transmission of an intertidal trematode parasite. Marine Biology, 158, 995-1003.

McCarthy, A. M. (1999). The influence of temperature on the survival and infectivity of the cercariae of Echinoparyphium recurvatum (Digenea: Echinostomatidae). Parasitology, 118, 383388.

Nielsen, D.L., Brock, M.A., Rees, G.N. and Baldwin, D.S., (2003). Effects of increasing salinity on freshwater ecosystems in Australia. Australian Journal of Botany, 51, 655-665.

Pietrock, M., \& Marcogliese, D. J. (2003). Free-living endohelminth stages: At the mercy of environmental conditions. Trends in Parasitology, 19, 293-299.

Preston, D. L., Orlofske, S. A., Lambden, J. P., \& Johnson, P. T. J. (2013). Biomass and productivity of trematode parasites in pond ecosystems. Journal of Animal Ecology, 82, 509-517. Sanzo, D., \& Hecnar, S. J. (2006). Effects of road de-icing salt (NaCl) on larval wood frogs (Rana sylvatica). Environmental Pollution, 140, 247-256.

Simmonds, N. E., \& Barber, I. (2016). The effect of salinity on egg development and viability of Schistocephalus solidus (Cestoda: Diphyllobothriidea). Journal of Parasitology, 102, 42-46.

Schotthoefer, A. M., Cole, R. A., \& Beasley, V. R. (2003). Relationship of tadpole stage to location of echinostome cercariae encystment and the consequences for tadpole survival. Journal of Parasitology, 89, 475-482.

Shostak, A.W. (1993). Survival of Petasiger nitidus (Digenea: Echinostomatidae) cercariae in relation to temperature, pH, and salinity. Canadian Journal of Zoology, 71, 431-434.

Stopper, G. F., Hecker, L., Franssen, R. A., \& Sessions, S. K. (2002). How trematodes cause limb deformities in amphibians. Journal of Experimental Zoology, 294, 252-263. 
Stuart, S. N., Chanson, J. S., Cox, N. A., Young, B. E., Rodrigues, A. S. L., Fischman, D. L., \& Waller, R. W. (2004). Status and trends of amphibian declines and extinctions worldwide. Science, 306, 1783-1786.

Studer, A., \& Poulin, R. (2012). Effects of salinity on an intertidal host-parasite system: Is the parasite more sensitive than its host? Journal of Experimental Marine Biology and Ecology, 412, $110-116$.

Studer, A., \& Poulin, R. (2013). Cercarial survival in an intertidal trematode: a multifactorial experiment with temperature, salinity and ultraviolet radiation. Parasitology Research, 112, 243249.

Todd, A. K., \& Kaltenecker, M. G. (2012). Warm season chloride concentrations in stream habitats of freshwater mussel species at risk. Environmental Pollution, 171, 199-206.

Venable, D. L., Gaudé, A. P., \& Klerks, P. L. (2000). Control of the trematode Bolbophorus confusus in channel catfish Ictalurus punctatus ponds using salinity manipulation and polyculture with black carp Mylopharyngodon piceus. Journal of the World Aquaculture Society, 31, 158-166.

Voyles, J., Berger, L., Young, S., Speare, R., Webb, R., Warner, J., Rudd, D., Campbell, R. and Skerratt, L.F., (2007). Electrolyte depletion and osmotic imbalance in amphibians with chytridiomycosis. Diseases of Aquatic Organisms, 77, 113-118. 


\section{CHAPTER 4: GENERAL DISCUSSION, CONCLUSION AND FUTURE WORK}

The primary objectives of this thesis were to determine the effects of road salts on larval amphibian susceptibility to infection by trematode parasites, as well as effects on the infectious stage (cercariae) that utilizes larval amphibians as hosts.

In Chapter 2, I examined the effects of road salt exposure on tadpole susceptibility to infection. I hypothesized that road salt would increase larval amphibian susceptibility to infection by lowering immunocompetence and anti-parasite behaviour of larval amphibians. Rana sylvatica (wood frogs) were exposed to the trematode Ribeiroia ondatrae and Rana pipiens (northern leopard frogs) were exposed to Echinostoma trivolvis after being subjected to environmentally-realistic solutions of road salts (control $=160 \mathrm{mg} / \mathrm{L}$, medium $=560 \mathrm{mg} / \mathrm{L}$ and high $=1050 \mathrm{mg} / \mathrm{L})$, and $($ control $=270 \mathrm{mg} / \mathrm{L}$, medium $=580 \mathrm{mg} / \mathrm{L}$, high $=1140 \mathrm{mg} / \mathrm{L})$, respectively. This was done by examining behaviour (activity level in presence of cercariae) and infection outcomes in R. sylvatica, and examining blood profiles and infection in R. pipiens. My findings for wood frogs support the hypothesis that anti-parasite behaviour will be reduced after road salt exposure and increase susceptibility to infection at my medium road salt concentration (400 mg/L). However, blood profiles of wood frogs were not available, and since the infection intensity of $R$. pipiens had no overall difference among treatments, the hypothesis that road salt will act as an immunosuppressant was rejected. There were more lymphocytes in the salt treatment conditions, but this did not explain differential infections.

In Chapter 3, I examined the effect of road salt on the free-swimming cercariae infectious stage of various trematode species, including $R$. ondatrae and E. trivolvis that were used in Chapter 2. Salt treatment had no effect on the mortality of the strigeid-type cercariae. In contrast, the survival of the armatae-type cercariae was negatively affected by treatment and time, but a 
clear difference between treatments was not apparent. Exposure to salt did not affect the survival of $R$. ondatrae cercariae. Similarly, treatment did not affect mortality of E. trivolvis. There was no significant interaction of treatment and time on the mortality of any type of cercariae. The final model for activity of the strigeid-type cercariae was significant because it decreased over time, and there were significant differences between the following treatments: control and 600 $\mathrm{mg} / \mathrm{L}, 200$ and $600 \mathrm{mg} / \mathrm{L}, 400$ and $600 \mathrm{mg} / \mathrm{L}$, and 600 and $800 \mathrm{mg} / \mathrm{L}$. There was no effect of treatment on the activity of the armatae-type cercariae. The overall model for the activity of $R$. ondatrae cercariae was significant because it decreased with time and at greater salt concentrations. For E. trivolvis, salt treatment had no effect on cercariae activity. There was no significant interaction of treatment and time on the activity of any type of cercariae.

As I showed that a reduction in anti-parasite behaviour occurs when $R$. sylvatica tadpoles are exposed to increased salinities, this can have wide range of implications for infection for aquatic vertebrates in salt-polluted water bodies if it reduces their resistance to parasitism. Notably, the trematode used to infect wood frogs, $R$. ondatrae, did not show increased mortality at similar salt concentrations, although there was a reduction in the activity of cercariae. In $R$. pipiens, I found that amphibian white blood cell profiles can change according to environmental perturbations such that an increase in lymphocytes occurs in more saline conditions. This could occur in many animals, and more work needs to be done to determine how various contaminants may affect larval amphibian immune system components in conjunction with road salts given that multiple stressors are known to have interactive effects (Sih et al., 2004). Furthermore, a reduction in cercarial ability to infect $R$. pipiens when exposed to the same saline solution might occur considering that infection intensities were higher in control conditions than in salt treatment conditions. Although the trematode used to infect the northern leopard frogs, $E$. 
trivolvis, was seemingly not affected by exposure to salt in terms of mortality or activity, the infection success of the parasites could be examined as well in future studies by exposing them to saline conditions but not their hosts and then examining their infection success. In addition, higher concentrations of road salt may be used on these trematode species, as well as their snail first intermediate host (Heliosoma trivolvis) in order to examine host-parasite interactions within all intermediate hosts and effects at extreme levels that might be found in some environments (see Chapter 1).

One limitation of this thesis is that $R$. sylvatica tadpoles were on average at Gosner developmental stage $\sim 37$ (Gosner, 1960), while $R$. pipiens were $\sim 28$, and it is known that tadpoles dramatically increase in their ability to resist trematode infections as they develop (Johnson et al., 2011). Younger tadpoles may be more prone to detrimental effects by increased salinity, and this should be examined. Moreover, in the case of $R$. pipiens, a major limitation was the low sample size for the blood smears. About $80 \%$ of tadpoles yielded usable blood, of which 27 slides were of sufficient quality to examine profiles with confidence. Another overall limitation of the larval amphibian study was that two different species of amphibians were used, and each with a different parasite, simply owing to availability. Further, behaviour was examined in $R$. sylvatica and not $R$. pipiens, while blood profiles were examined in $R$. pipiens and not $R$. sylvatica. A study employing both measures for a single species would be optimal, as well as the ability to compare host species in a controlled manner. For future directions, each species of amphibian should be exposed to both parasite types while quantifying behaviour and blood profile of both. Higher concentrations of salt could also be used to reflect urban environments (Howard and Beck, 1993; Sanzo and Hecnar, 2006), or a longer chronic study could be done to examine long-term effects. 
My thesis research will contribute to scientific knowledge because it is the first one to examine the effects of road salts in the context of host-parasite interactions in larval amphibians, let alone any freshwater organism. While other studies explored impacts of road salts on amphibian mortality and morbidity (Sanzo and Hecnar, 2006; Findlay and Kelly, 2011), none took such a comprehensive examination. Here, I looked at blood profiles, anti-parasite behaviour and infection rates as influenced by environmentally-realistic concentrations of road salts. If a link can be made between differential infection patterns, anti-parasite behaviour, and stressmediated effects on immune parameters, then a mechanistic framework by which road salts act on larval amphibians could be made with some further investigations. This knowledge will benefit conservation efforts and perhaps help to inform road salt use policies given the high likelihood that elevated salinity has detrimental effects on aquatic communities. 


\section{References:}

Gosner, K. (1960). A Simplified Table for Staging Anuran Embryos and Larvae with Notes on Identification. Herpetologica, 16, 183-190.

Howard, K. W. F., \& Beck, P. J. (1993). Hydrogeochemical implications of groundwater contamination by road de-icing chemicals. Journal of Contaminant Hydrology, 12, 245-268.

Johnson, P. T. J., Kellermanns, E., \& Bowerman, J. (2011). Critical windows of disease risk: Amphibian pathology driven by developmental changes in host resistance and tolerance, Functional Ecology, 25, 726-234.

Sanzo, D., \& Hecnar, S. J. (2006). Effects of road de-icing salt ( $\mathrm{NaCl})$ on larval wood frogs (Rana sylvatica). Environmental Pollution, 140, 247-256.

Sih, A., Bell, A. M., \& Kerby, J. L. (2004). Two stressors are far deadlier than one. Trends in Ecology \& Evolution, 19, 274-276. 